\title{
Systematic review of fever, febrile convulsions and serious adverse events following administration of inactivated trivalent influenza vaccines in children
}

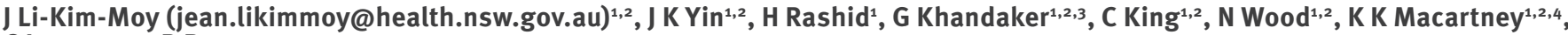
C Jones ${ }^{2,3,4,5}$, R Booy $^{1,2,4,5}$

1. National Centre for Immunisation Research and Surveillance, The Children's Hospital at Westmead, New South Wales, Australia

2. Sydney Medical School, The University of Sydney, New South Wales, Australia

3. Centre for Perinatal Infection Research, The Children's Hospital at Westmead, New South Wales, Australia

4. Department of Microbiology and Infectious Diseases, The Children's Hospital at Westmead, New South Wales, Australia

5. Marie Bashir Institute for Infectious Diseases and Biosecurity, University of Sydney, New South Wales, Australia

Li-Kim-Moy J, Yin JK, Rashid H, Khandaker G, King C, Wood N, Macartney KK, Jones C, Booy R. Systematic review of fever, febrile convulsions and serious adverse events following administration of inactivated trivalent influenza vaccines in children. Euro Surveill, 2015;20(24):pii=21159. Available online: http://www.

eurosurveillance.org/ViewArticle.aspx?Articleld=21159

In 2010, increased febrile convulsions (FC) occurred after administration of inactivated trivalent influenza vaccine (TIV) in Australia. We systematically reviewed the rates of fever, FC and serious adverse events (SAEs) after TIV, focussing on published and unpublished clinical trial data from 2005 to 2012, and performed meta-analysis of fever rates. From 4,372 records in electronic databases, 18 randomised controlled trials (RCTs), 14 non-randomised clinical trials, six observational studies and 12 registered trials (five RCTs and seven non-randomised) were identified. In published RCTs, fever $\geq 38^{\circ} \mathrm{C}$ rates after first dose of non-adjuvanted TIV were $6.7 \%$ and $6.9 \%$ for children aged $6-35$ months and $\geq 3$ years, respectively. Analysis of RCTs by vaccine manufacturer showed pooled fever estimates up to $5.1 \%$ with Sanofi or GlaxoSmithKline vaccines; bioCSL vaccines were used in two non-randomised clinical trials and one unpublished RCT and were associated with fever in $\mathbf{2 2 . 5}-\mathbf{3 7 . 1} \%$ for children aged $6-35$ months. In RCTs, FCs occurred at a rate of 1.1 per 1,000 vaccinated children. While most TIVs induced acceptably low fever rates, bioCSL influenza vaccines were associated with much higher rates of fever in young children. Future standardised study methodology and access to individual level data would be illuminating.

\section{Introduction}

is a common respiratory viral infection with a substantial disease burden in children younger than five years, of whom between nine and 45 per 10,000 need hospital admission each year in developed countries [1-4]. Vaccination is the leading strategy to combat influenza. The recommendations for influenza vaccination have been progressively expanded and now include all healthy children aged six months and older in the United States (US) and several European countries
$[5,6]$. The United Kingdom's (UK) Joint Committee on Vaccination and Immunisation (JCVI) recommended vaccination of all children two to 17 years of age with live attenuated influenza vaccine (LAIV) from the 2013/14 season onwards, although implementation was being staggered, commencing with two and three year-old children in the first year [7]. In Australia, TIV is funded nationally for any child older than six months with medical conditions predisposing to severe influenza, and in one state (Western Australia) also for healthy children aged six to 59 months [8].

In 2010, an unexpected and marked increase in fever and febrile convulsion (FC) rates in Australian children younger than five years was detected following receipt of the seasonal inactivated trivalent influenza vaccine (TIV). Influenza vaccination for children five years and younger was briefly suspended. The increase in FC (estimated to be between five and seven events per 1,000 vaccinated children) was related only to one brand of TIV, manufactured by bioCSL (Fluvax and Fluvax Junior) [9]. Despite its subsequent deregistration for children younger than five years, public concerns about vaccine safety have persisted, leading to markedly lower influenza vaccine uptake, especially in Western Australia [10]. Published data documenting the frequency and severity of fever after TIV in children are sparse. Furthermore, the age bands reported and fever cut-off values used vary widely, with limited application of standardised definitions such as those from the Brighton Collaboration [11]. We therefore systematically reviewed the evidence for influenza vaccine safety in children to examine the rates of fever, FCs and serious adverse events (SAEs as per standard definition [12]) associated with contemporary TIVs. We also aimed to assess the effect of age, vaccine type 
(adjuvanted or not) and vaccine manufacturer on the frequency of these adverse events.

\section{Methods}

An electronic literature search, without language restriction, was performed using Medline, Embase, Cochrane Library databases, LILACS, SCOPUS, and Web of Science for studies published between January 2005 and March or April 2012. Our focus was on contemporary vaccines hence our restriction to this publication period. Both controlled vocabulary and text-word terms were used, including 'immunization', 'influenza vaccines', 'influenza, human', 'safety', 'fever', 'seizures, febrile', 'adverse event/effect', 'product surveillance, post-marketing', 'Guillain-Barré syndrome', together with 'child' or 'infant.' A listing of the specific databases, search strategy and coverage dates are available from the corresponding author upon request. In addition, a search was performed within Clinicaltrials. gov, a globally used registry, for phase 2,3 or 4 clinical trials using TIV in a paediatric population.

We included randomised controlled trials (RCTs), non-randomised clinical trials (with or without a control group) and observational studies. Studies were included if they (i) involved the use of inactivated seasonal TIV, administered intramuscularly, in at least one study arm; (ii) involved healthy children up to 17 years of age; and (iii) presented safety data in an extractable format. Studies were excluded if they only involved children younger than six months or only populations with chronic illness and/or immunocompromise. We analysed data by age band, study design, vaccine type and vaccine manufacturer, where possible. Dose 1 and dose 2 data were analysed separately. Febrile convulsion rates and SAEs were noted, if documented.

The quality of RCT studies was assessed by examining bias using the Cochrane Collaboration's tool for assessing risk of bias [13]; non-randomised clinical trials were assessed by the Effective Public Health Practice Project (EPHPP) Quality Assessment tool, as this better encompassed variation $[14,15]$.

Meta-analysis was conducted on fever data using the Brighton Collaboration case definition of $\geq 38^{\circ} \mathrm{C}$ from any source (axillary, oral or rectal) [11]. Due to variability in study methods and a lack of placebo-controlled studies, we conducted a proportion meta-analysis of fever rates using similar single-arm data from trials (StatsDirect statistical software version 2.7.9) to calculate pooled fever proportions. This method has been used previously in systematic reviews across different disciplines [16-21]. A random effects model with the DerSimonian-Laird method was used to account for variability in study design and results. The $\mathrm{I}^{2}$ statistic was used as a measure of heterogeneity of pooled estimates [13].

We conducted sensitivity analyses of meta-analyses to see if exclusion of high-risk RCTs, or those non-randomised clinical trials rated as weak, reduced heterogeneity. If heterogeneity was unchanged, then all available studies were used for analysis.

\section{Results}

Of the 4,372 studies initially identified (Figure), 18 RCTs [22-39], 14 non-randomised clinical trials [40-53], and six observational studies [54-59] were eligible for inclusion. The clinical trial registry search yielded 12 additional relevant studies (five RCTs and seven nonrandomised trials). We found substantial variation in study methods, fever definitions, age of participants, year of study, length of follow-up for solicited adverse events, vaccine types and brands.

\section{Characteristics of randomised controlled trials} In the 18 randomised control trials (Table 1), a total of 22,484 subjects were enrolled, of whom 16,474 received TIV and had safety data collected. Multiple study designs were encountered in terms of comparison groups; for non-adjuvanted TIV, comparison with placebo was only found in one study [33]. Five studies examined adjuvanted vaccines (MF59 or virosomal adjuvant) in at least one study arm [30,31,34,35,39].

Classification of fever varied across studies, but a majority of studies $[22,25,27,29-31,34,35,37,38]$ provided data on fever $\geq 38^{\circ} \mathrm{C}$. We used these studies for meta-analysis of fever rate and one additional study [39], where we assumed a fever definition of $\geq 38^{\circ} \mathrm{C}$ based on two similar studies by the same lead author $[31,35]$.

Study quality varied using the Cochrane Collaboration's tool for assessing risk of bias. Five studies were assessed as being at low risk of bias [26,31,33-35]. Ten studies had medium risk of bias $[22,24,25,27-$ $30,32,38,39]$, and three studies had high risk $[23,36,37]$. Sensitivity analyses limited only to low-risk studies were not feasible; there were too few studies, and two did not use a fever definition of $\geq 38^{\circ} \mathrm{C}$.

\section{Characteristics of non-randomised clinical trials}

Fourteen non-randomised trials were identified (Table 2). Of the 8,119 total participants, 7,901 received TIV and had safety data available. Two studies $[48,52]$ were follow-on studies from previous RCTs. Most used within-study age cohorts for comparison and/or had no control group [40,42,44-47,49,50,53]. For fever meta-analysis, we used five studies with fever defined as $\geq 38^{\circ} \mathrm{C}[40,41,48,49,52]$ and two $[47,53]$ where fever was $\geq 37.5^{\circ} \mathrm{C}$ axillary or $\geq 38^{\circ} \mathrm{C}$ orally (still meeting the Brighton Collaboration criteria [11]).

Overall, a high risk of bias was observed due to lack of randomisation and open-label study designs, without blinding in most studies. In addition, many studies were lacking control groups. Five studies [41,43,48,49,51] were assessed as being of 'moderate' strength while nine studies were 'weak' $[40,42,44-47,50,52,53]$. 


\section{FIGURE}

Results of literature search for fever, febrile convulsions and serious adverse events following administration of inactivated trivalent influenza vaccine in children, and studies analysed
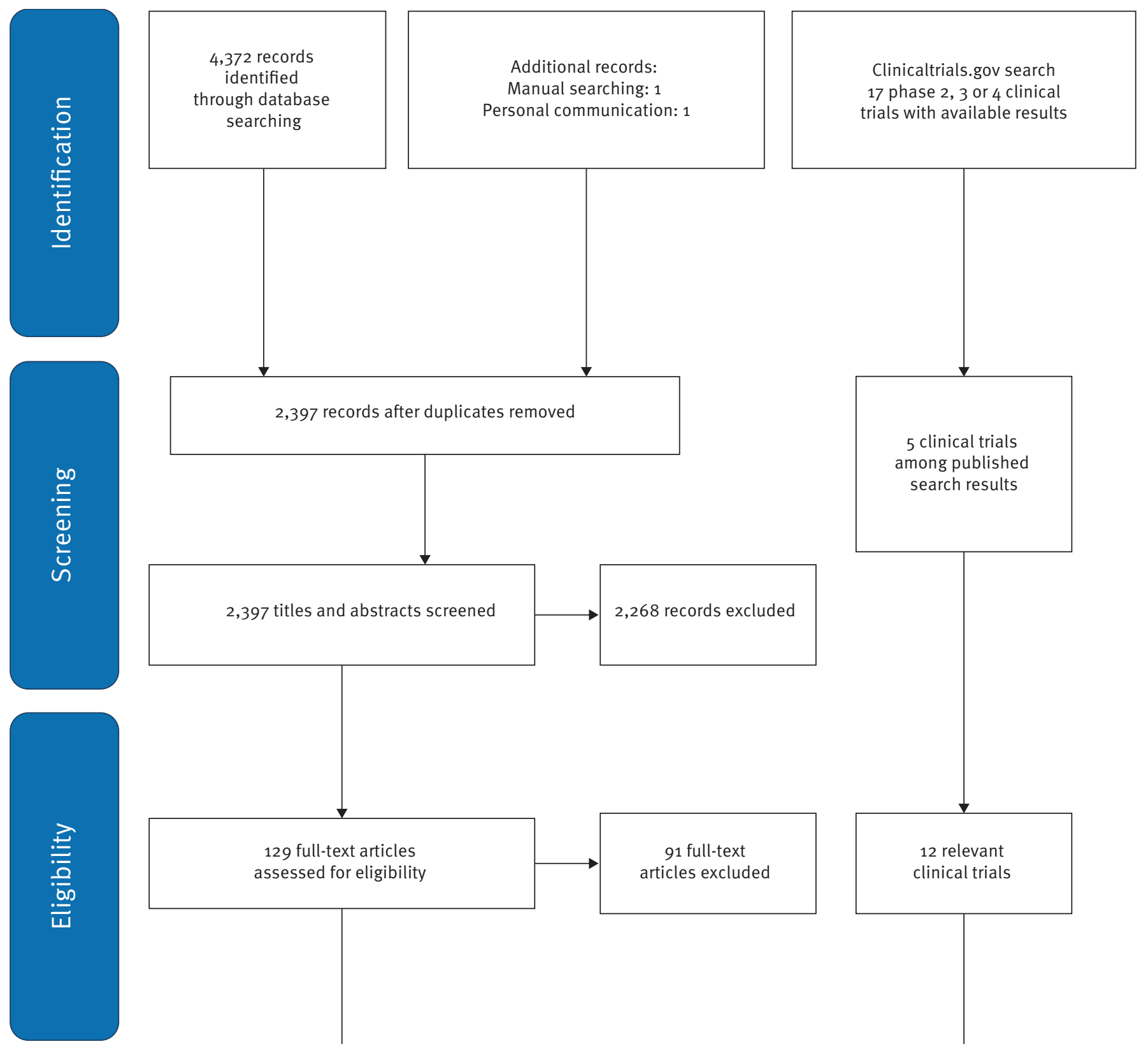

2,397 records after duplicates removed
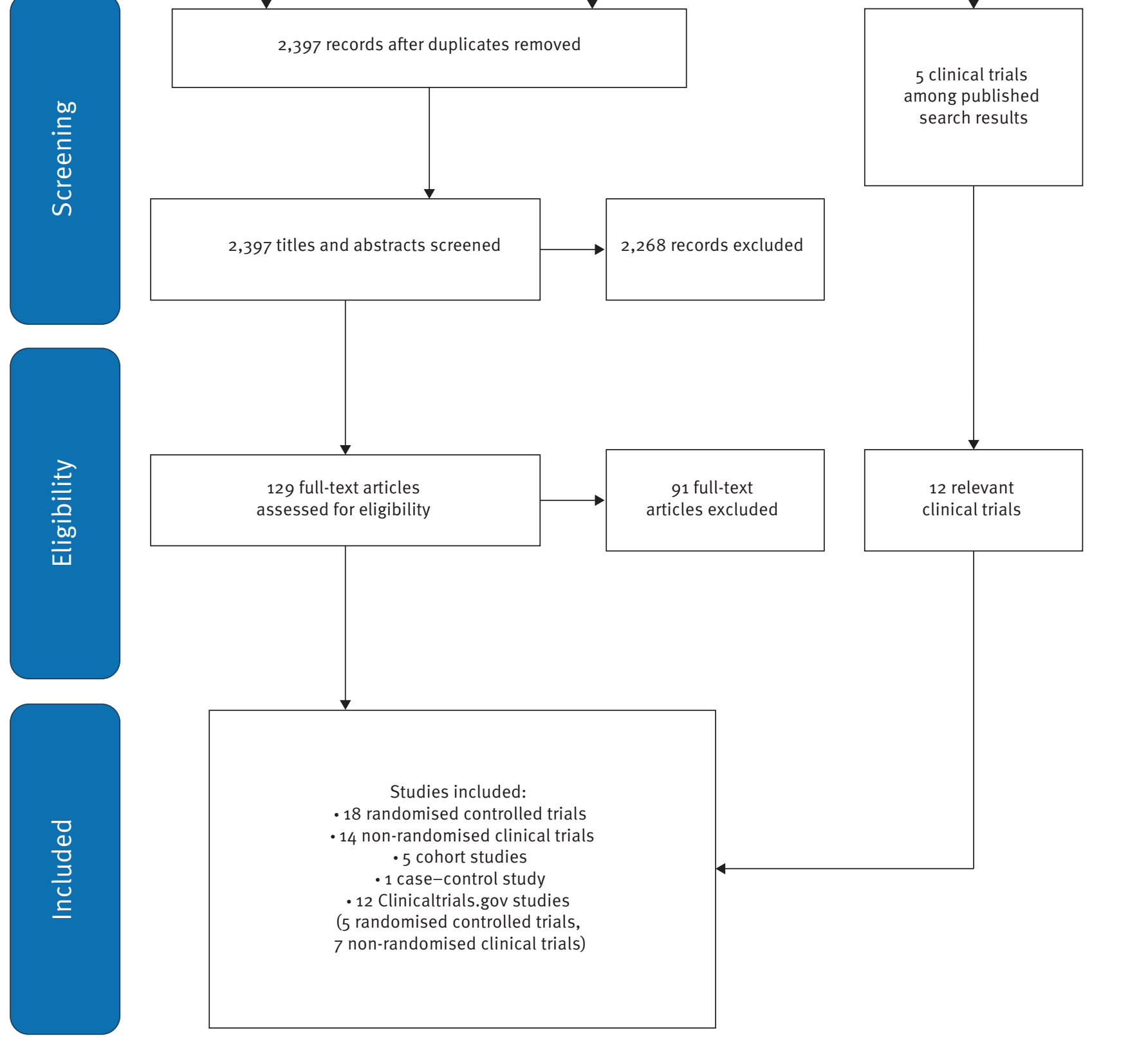

Adapted from PRISMA 2009 Flow Diagram [73]. 


\begin{tabular}{|c|c|c|c|c|c|c|c|c|c|c|c|c|c|c|}
\hline & $\begin{array}{l}\circ 0 \\
\circ \\
0 \\
1 \\
\hat{0}\end{array}$ & 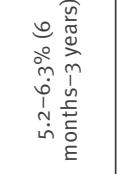 & 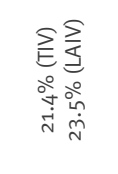 & $\stackrel{\circ}{\circ} \stackrel{\circ}{m}$ & 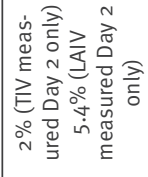 & 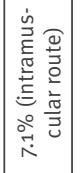 & $\begin{array}{l}\text { i̊ } \\
\text { i } \\
\stackrel{1}{+} \\
\dot{f}\end{array}$ & 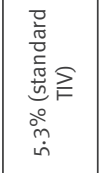 & $\stackrel{\text { }}{\stackrel{\circ}{m}}$ & 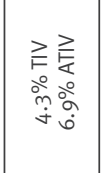 & 离 & ঙั & $\begin{array}{l}\stackrel{\circ}{\circ} \\
\hat{\circ} \\
\stackrel{1}{\wedge}\end{array}$ & 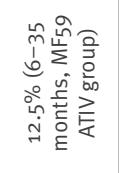 \\
\hline & $\begin{array}{l}\frac{E}{\bar{\Xi}} \\
\sum \\
\sum\end{array}$ & $\begin{array}{l}\text { 商 } \\
\text { I }\end{array}$ & 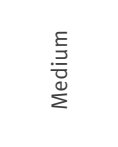 & 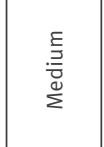 & 3 & 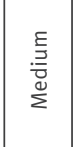 & 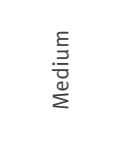 & 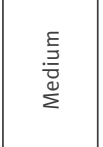 & 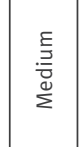 & 宐 & $\begin{array}{l}\underline{\underline{\underline{z}}} \\
\stackrel{\bar{\nu}}{\Sigma}\end{array}$ & $\underline{3}$ & z) & 3 \\
\hline 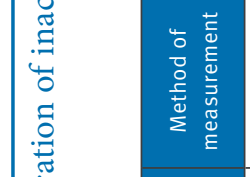 & 宸 & 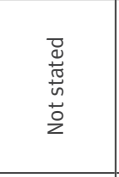 & 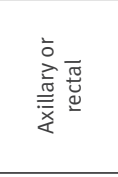 & 宸 & 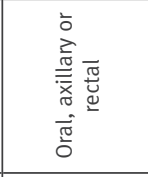 & 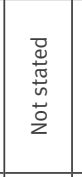 & 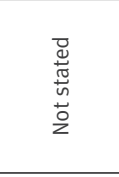 & 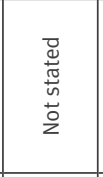 & 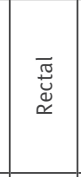 & 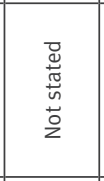 & 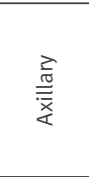 & 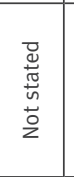 & $\begin{array}{l}\overline{\widetilde{\widetilde{g}}} \\
\stackrel{\widetilde{u}}{ }\end{array}$ & 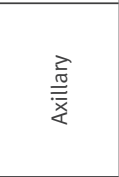 \\
\hline 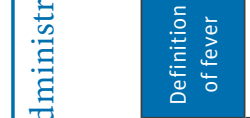 & 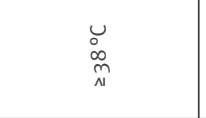 & 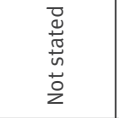 & 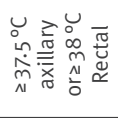 & $\underset{\substack{u \\
\infty \\
N}}{N}$ & 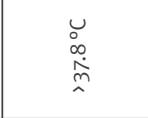 & 品 & 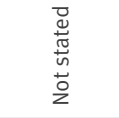 & $\underset{\substack{u \\
\infty \\
N}}{N}$ & 落 & 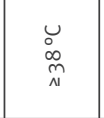 & 薍 & $\begin{array}{l}u \\
o \\
\infty \\
\stackrel{N}{N} \\
\end{array}$ & 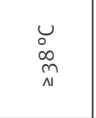 & $\begin{array}{l}\cup \\
0 \\
N \\
N\end{array}$ \\
\hline 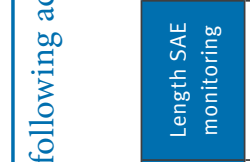 & 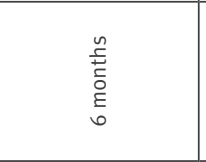 & $\begin{array}{l}\frac{n}{3} \\
\frac{\tilde{J}}{m} \\
m\end{array}$ & 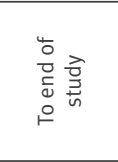 & 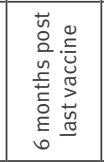 & 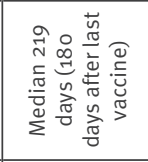 & 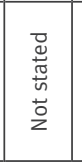 & 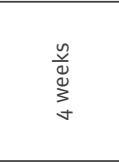 & 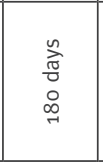 & 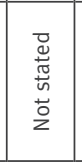 & 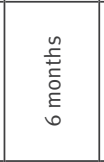 & 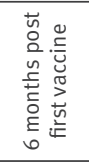 & 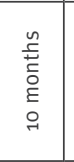 & 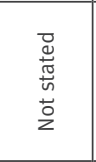 & 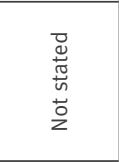 \\
\hline 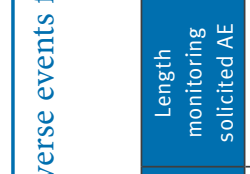 & $\begin{array}{l}\frac{n}{\tilde{z}} \\
\text { 奠 }\end{array}$ & 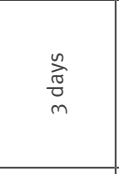 & $\begin{array}{l}\frac{n}{30} \\
\frac{j}{7} \\
\bar{y}\end{array}$ & 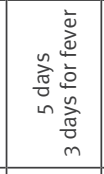 & 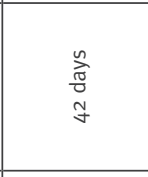 & 倠 & 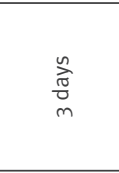 & $\begin{array}{l}\frac{n}{0} \\
\text { 啇 }\end{array}$ & 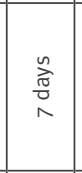 & 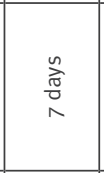 & 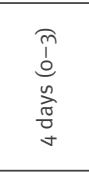 & $\begin{array}{l}\stackrel{n}{\tilde{J}} \\
\stackrel{\sigma}{\sigma} \\
\vec{\sigma}\end{array}$ & \begin{tabular}{l} 
no \\
oj \\
\multirow{y}{y}{}
\end{tabular} & 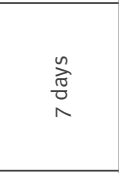 \\
\hline 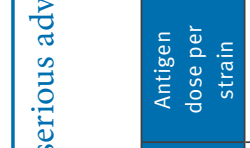 & 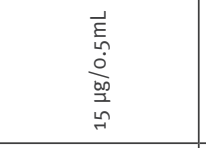 & 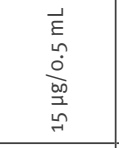 & 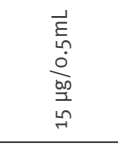 & 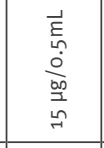 & 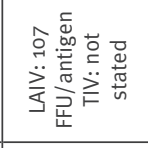 & 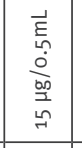 & 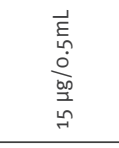 & 埌 & 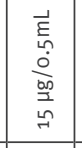 & 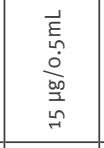 & 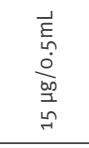 & 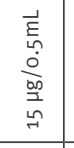 & 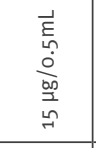 & 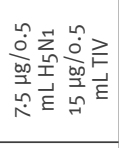 \\
\hline 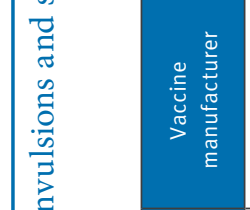 & 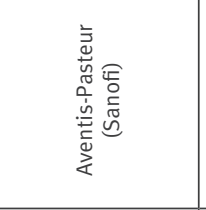 & 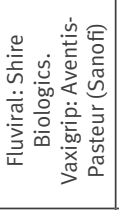 & 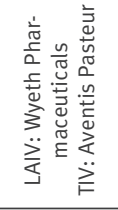 & 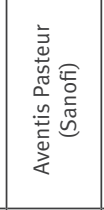 & 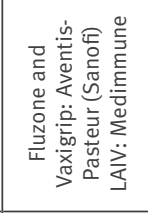 & 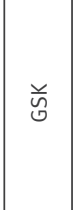 & 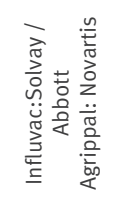 & 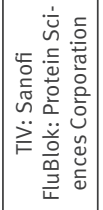 & 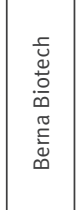 & 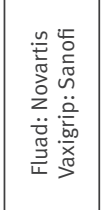 & 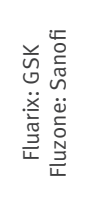 & 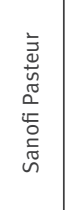 & 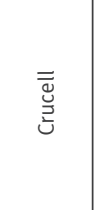 & $\begin{array}{l}\frac{n}{\underline{\underline{E}}} \\
\frac{5}{2} \\
\frac{0}{2}\end{array}$ \\
\hline 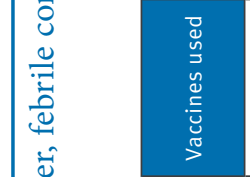 & $\gtreqless$ & 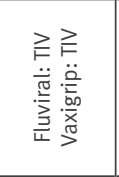 & $\gtreqless \gtreqless$ & $\gtreqless$ & 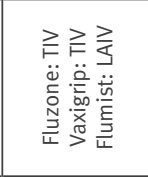 & 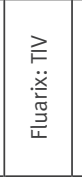 & 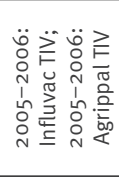 & 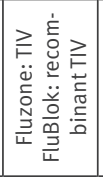 & 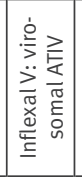 & 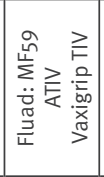 & 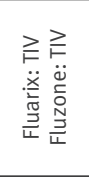 & 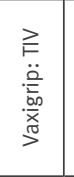 & 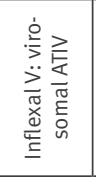 & 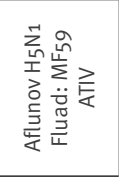 \\
\hline 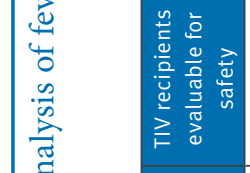 & के & $\stackrel{\infty}{\wedge}$ & $\begin{array}{l}\infty \\
\substack{\infty \\
-\rightarrow}\end{array}$ & ్ֶర & $\stackrel{\substack{a \\
\dot{q}}}{2}$ & in & $\stackrel{\circ}{\circ}$ & $\stackrel{\circ}{:}$ & \& & $\stackrel{a}{\text { d }}$ & $\underset{N}{\tilde{N}}$ & $\vec{\lambda}$ & $\tilde{\omega}$ & $\hat{m}$ \\
\hline 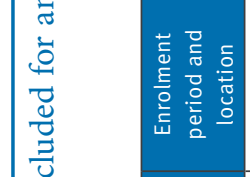 & 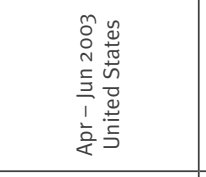 & 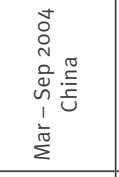 & 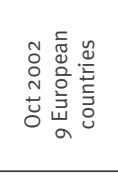 & 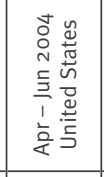 & 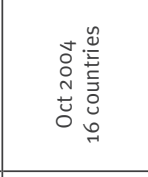 & 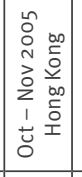 & 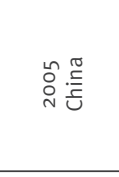 & 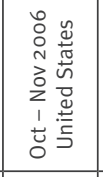 & $\mid$ & 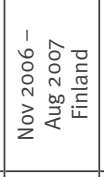 & 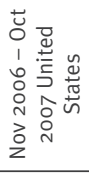 & 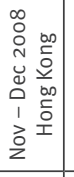 & 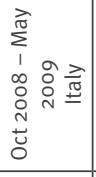 & 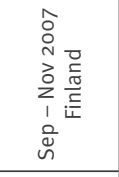 \\
\hline 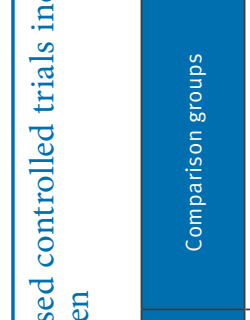 & 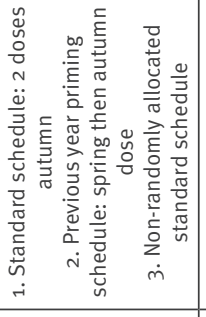 & 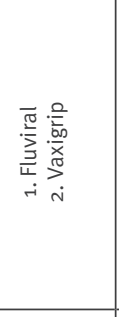 & 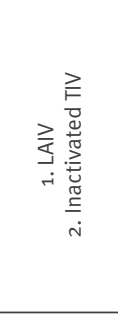 & 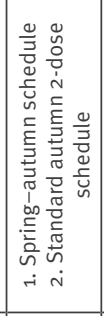 & 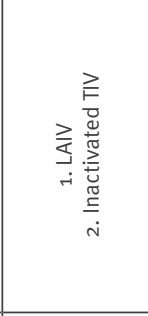 & 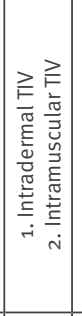 & 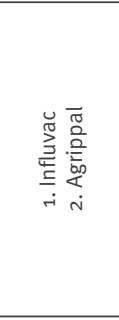 & 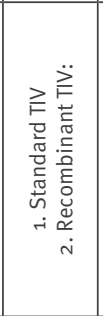 & 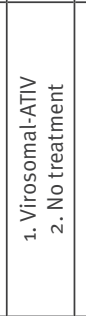 & 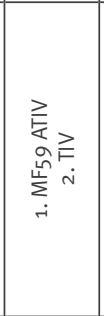 & 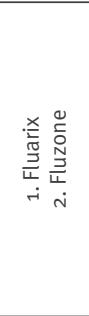 & 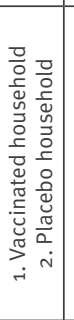 & 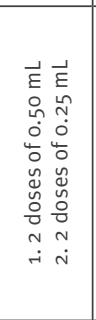 & 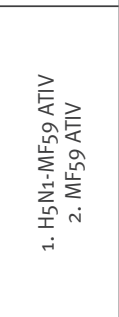 \\
\hline 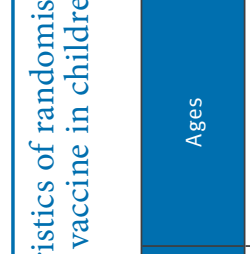 & 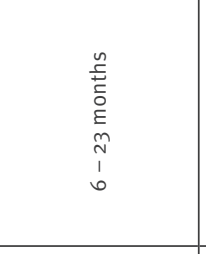 & 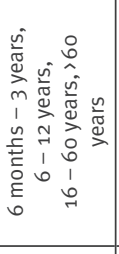 & 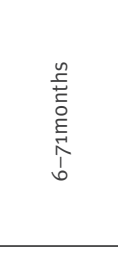 & 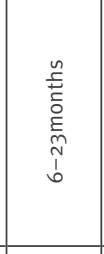 & 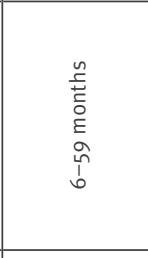 & 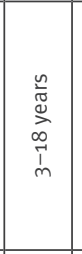 & 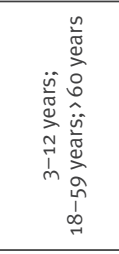 & 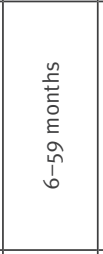 & 商 & 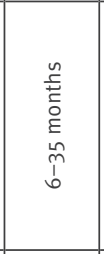 & 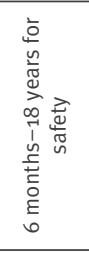 & 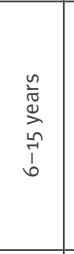 & 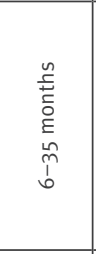 & 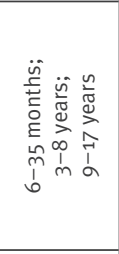 \\
\hline 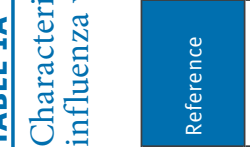 & 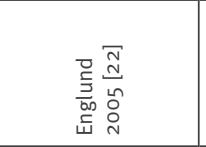 & 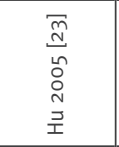 & 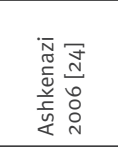 & 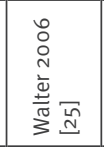 & 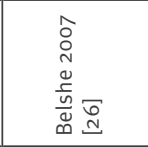 & 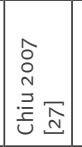 & $\begin{array}{l}\infty \\
\vdots \\
\stackrel{0}{N} \\
\stackrel{\Xi}{N} \underset{N}{N}\end{array}$ & 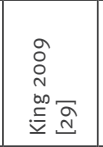 & 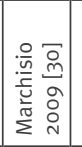 & 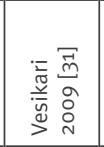 & 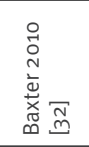 & 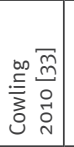 & 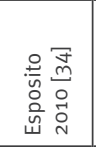 & 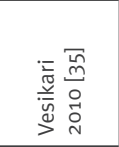 \\
\hline
\end{tabular}




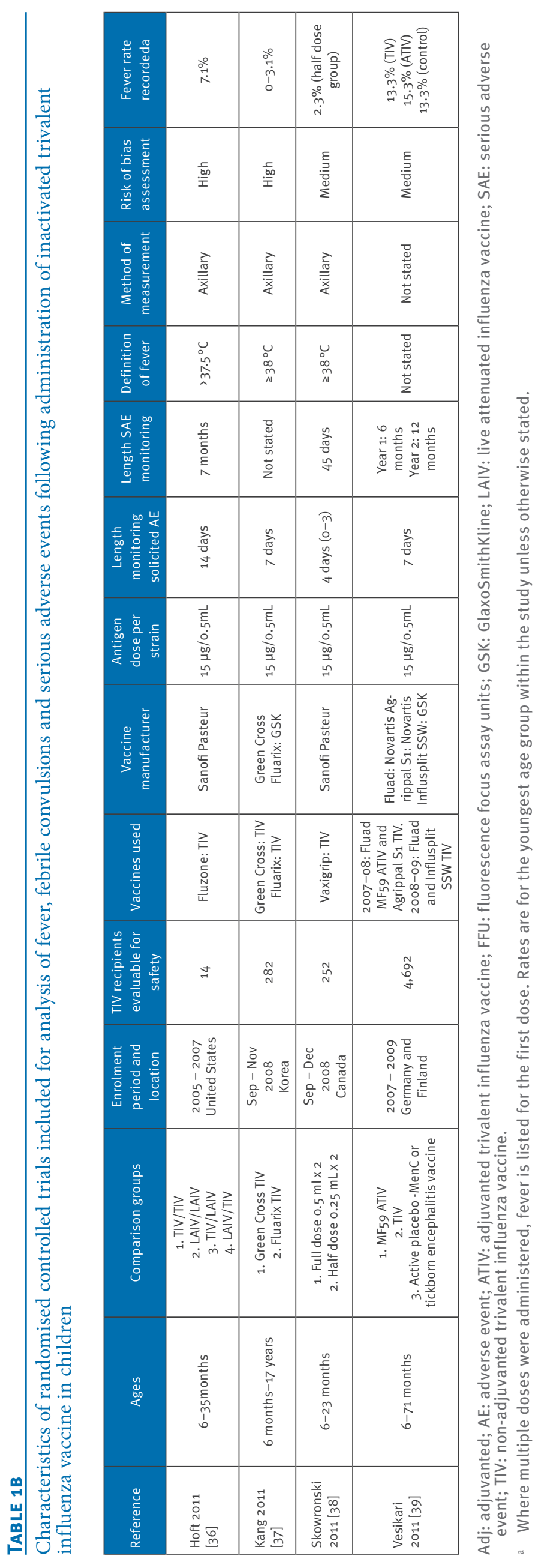


Adverse events following immunisation

Fever

Pooled estimates of fever obtained using proportion meta-analysis of studies are shown in Table 3 and Table 4 .

Non-adjuvanted vaccines in children six to 35 months of age

The pooled proportion estimate of fever was 6.7\% (95\% confidence interval (CI):3.0-11.8) after first dose of TIV based on five eligible RCTs $[22,29,31,38,39]$. None of these RCTs had a high risk of bias. Analysis of five nonrandomised clinical trials $[40,41,47,49,53]$ provided higher first-dose fever estimates of $17.7 \%(95 \% \mathrm{Cl}$ : 11.3-25.2), largely due to the inclusion of two studies of bioCSL vaccines $[47,53]$ that reported higher rates of post-vaccination fever. Rates after second doses are listed in Table 3 and Table 4.

\section{Non-adjuvanted vaccines in children three to 17 years of age}

There were only two eligible two-dose RCTs in this age group [29,39]. The pooled proportion estimate of fever for children three years and older was $6.9 \%(95 \% \mathrm{Cl}$ : 5.2-8.7) for dose 1 . Meta-analysis of non-randomised clinical trials revealed more fever, $15.1 \%(95 \% \mathrm{Cl}$ : 13.3-17.0), again due to the inclusion of studies using bioCSL vaccines [47,53]. Second doses caused lower rates of fever.

\section{Adjuvanted vaccines}

Three RCTs used Fluad (Novartis), an MF59-adjuvanted vaccine which remains investigational and unlicensed in the paediatric age group, and included children aged from six months to 17 years $[31,35,39]$. Two of these studies $[31,35]$ had low risk of bias and one was medium risk [39]. Point estimates of fever were higher than corresponding values for non-adjuvanted vaccines; however confidence intervals were wide due to the limited number of subjects. For children six to 35 months of age, first-dose pooled fever estimates were $11.9 \%$ (95\% Cl: 6.8-18.3). Data were more limited on children three years and older with pooled fever rates of $10.3 \%$ (95\% Cl: 1.1-27.0). Again, second doses elicited less fever. A small single non-randomised clinical trial reported fever rates of $16.0 \%$ for age $16-35$ months, and $11.1 \%$ for age 36-48 months [48].

Direct within-study comparison between MF59-ATIV and non-adjuvanted TIV fever rates in two RCTs $[31,39]$ showed significantly higher fever rates only in the subset of children aged 36-71 months in the ATIV group compared with the TIV group in one study $(17.5 \%$ and $6.7 \%$, respectively, for dose $1, p<0.001$ ) [39]. Two small studies of Inflexal V (Berna Biotech) virosomal-adjuvanted vaccine $[30,34]$ showed pooled fever rates of $5.5 \%$ (95\% Cl: 1.3-12.3) (Table 3).
Post-vaccination fever, analysis by vaccine manufacturer Fever estimates were calculated for Sanofi Pasteur, GlaxoSmithKline (GSK), Novartis, and bioCSL vaccines. Studies were grouped together, despite some variation in definition of fever, to maximise the number of studies evaluated. Data were analysed within age bands of six to 35 months and three to 17 years; data for dose 1 and 2 were analysed separately where possible. Data presented below covers non-adjuvanted vaccines. As MF59-adjuvanted (Novartis) and virosomal-adjuvanted (Berna Biotech) vaccines were produced by single manufacturers, corresponding data for adjuvanted vaccines are listed within the adjuvanted sections of Table 3 and Table 4.

\section{Randomised studies}

RCTs using Sanofi Pasteur products (Vaxigrip, Fluzone) $[22-26,29,31-33,36,38]$, GSK's Fluarix [27,32,37], and Novartis's Agrippal [28] were examined (Table 3). Overall, fever rates were comparable between these brands of vaccine. For Sanofi products, in the age bands six to 35 months and three to 17 years, pooled first-dose fever rates were $5.1 \%$ and $4.4 \%$ respectively. Fever estimates were $4.7 \%$ (95\% Cl: 0.9-11.1) for GSK's vaccine and $4.0 \%$ (95\% Cl: $1.5-10.5)$ for Novartis's vaccine (analysis by age bands was not possible). Where applicable, high-risk studies were excluded, but this did not change heterogeneity.

Non-randomised studies

Fever rates were relatively high in Sanofi studies after the first dose in young children aged six to 35 months (16.9\%; 95\% Cl: 12.6-21.6), but lower in three to eight year-old children (0.4\%; 95\% Cl: 0-2.4). GSK studies did not allow analysis by these age bands; the average childhood fever rate was 5.6\% (95\% Cl: 2.9-9.1).

In contrast, markedly higher fever rates were reported in the two studies of bioCSL vaccine [47,53]. Both were uncontrolled clinical trials and had different age cohorts. Pooled estimates of fever were elevated after the first dose in children aged six to 35 months and three to eight years $(26.4 \% ; 95 \% \mathrm{Cl}: 21.0-32.3$ and 18.8\%; 95\% Cl 15.9-21.9, respectively). Children nine years and older had a considerably lower fever rate (5.0\%; 95\% Cl: 3.3-7.7). For second doses, fever rates were high for children aged six to 35 months (19.4\%; $95 \% \mathrm{Cl}: 15.3-23.9)$ and were elevated, to a lesser extent, for three to eight year-old children (9.7\%; $95 \%$ $\mathrm{Cl}$ 7.7-11.9). Second-year booster doses of bioCSL vaccine with two vaccine strain changes, described in one study [47], showed even higher rates of fever, both in those aged six to 35 months (39.5\%; 95\% Cl: $28.4-$ 51.4 ) and in those aged three to eight years (27.0\%; 95\% Cl 21.0-33.8) (Table 4).

Serious adverse events (SAEs)

'Serious adverse events' were not routinely defined in studies but was we assumed them to be the standard definition commonly used in clinical trials [12]. 


\section{Randomised Studies}

Among 15 RCTs of adjuvanted and non-adjuvanted vaccines [22,24-26,28-35,37-39] with 14,668 vaccinated individuals, 14 possibly or probably related SAEs were documented. Proportion meta-analysis yielded a pooled SAE rate of 1.2 per 1,000 vaccinated children. SAEs, where specifically described, included suspected allergic reactions to the vaccine, febrile and afebrile seizures after vaccination, new-onset diabetes, gait disorder, pneumonia, wheezing and viral gastroenteritis. A death was reported in one TIV recipient [26], deemed unrelated to the vaccination.

\section{Non-randomised studies}

Eight related SAEs were reported in non-randomised clinical trials among 7,655 vaccinated children (pooled estimate: 1.85 events per 1,000) [40,41,43-53]. SAEs described included post-vaccination fever requiring hospitalisation, bronchial hyperreactivity, bronchopneumonia, dysentery diarrhoea and distension of the abdomen, increased respiratory secretions, fever and vomiting or one $\mathrm{FC}$ and vomiting. One unrelated death was reported [51].

\section{Febrile convulsions}

\section{Randomised studies}

Using similar proportion meta-analysis of vaccinated study arms, we calculated an FC rate of 1.1 per 1,000 (95\% Cl: 0.51-1.9) using three large RCTs $[26,32,39]$ ( $n=7,439$ children up to 59 or 71 months of age) that specifically reported FC as adverse events, and six RCTs $(1,207$ children aged up to 59 months) $[22,25,29,31,34,38]$ that reported no related SAEs and by assumption, no FC. One of the three studies that reported on FC [32] included one vaccine-related seizure within a subset of 1,496 children aged 6-59 months ( 0.67 events per 1,000 children). Another study [26] reported two vaccine-related FCs among 4,173 children aged six to 59 months following TIV administration (0.48 events per 1,000). A third study [39], the only one incorporating a non-TIV control group, found similar FC rates in three study arms of non-adjuvanted TIV (2.82 per 1,000; $n=1,770), M F 59$ ATIV (2.59/1,000; $n=1,934)$ and active control vaccine $(4.05 / 1,000 ; n=988)$ in children six to 71 months of age. However, no comment was made if these FCs were causally related to vaccination.

\section{Non-randomised studies}

Two vaccine-related FCs were recorded in two nonrandomised clinical trials (in total 2,269 evaluable children, 854 aged between six months and three years) $[47,53]$. Both studies used bioCSL TIV and had high rates of fever, particularly in younger vaccine recipients, compared with other non-randomised study results. Rates were not calculated due to the unavailability of denominator data within the susceptible age range.
Estimates of fever from unpublished clinical trial data (Clinicaltrials.gov)

Results from unpublished clinical trials are summarised in Table 5 and Table 6. Insufficient information on study methodology precluded detailed comparisons between studies. Temperature definitions were largely unavailable. There were five RCTs, of which three were double-blind RCTs (NCTo0464672, NCTo0764790, NCTo0959049). One of these, an RCT (NCToo959049) which was unpublished at the time of our literature search [6o], directly compared Afluria (bioCSL) with Fluzone (Sanofi) across several age bands. It was conducted in the US between September 2009 and May 2010 and defined fever as either $\geq 37.5^{\circ} \mathrm{C}$ axillary or $\geq 38^{\circ} \mathrm{C}$ oral. Afluria was associated with significantly higher rates of fever compared with Fluzone for first doses in children aged six to 35 months ( $37.1 \%$ vs $13.6 \%$, respectively, $p<0.0001$ ) and three to eight years $(21.8 \%$ vs $9.4 \%$, respectively, $p=0.0001)$. There were no significant differences in fever following second doses or after single doses in children aged nine to 17 years.

Fever rates in other RCTs ranged from 6.2 to $10.7 \%$ for children aged six to 35 months, $0-11.0 \%$ in children aged three to eight or nine years, and $0-3.8 \%$ in children aged nine or 10 to 17 years. Seven small non-randomised clinical trials were identified, all using Sanofi vaccine. Age ranges were variable, precluding detailed comparison. Fever rates varied widely (Table 6).

Observational studies: cohort studies and casecontrol studies

The six included observational studies [54-59] are summarised in Table 7. A study of inactivated virosomaladjuvanted TIV (Inflexal V) in 966 vaccinated children reported fever in $0.52 \%$, without comparison data from the unvaccinated cohort [54]. One retrospective casecontrol study assessed safety outcomes within $\mathbf{4 2}$ days after TIV in 13,383 children $(3,697$ vaccinated children aged six to 23 months, with three age- and sex-matched controls) from a US medical group patient database [55]. No significant associations were detected for any condition, including fever or seizures, except for pharyngitis and second TIV doses.

A large population-based retrospective cohort study investigated the safety of TIV in children six to 23 months of age [56]. It examined the risk of medically attended events (MAE) after TIV in 45,356 children (69,359 vaccinations) from 1991 to 2003. Using a casecrossover method, MAE in four risk windows post vaccination was compared with two control periods, one before and one after receiving TIV. No significant associations between TIV vaccination and any MAE, including FCs, were found. Another retrospective cohort study examined children aged 24 to 59 months in the US Vaccine Safety Datalink (VSD) over four influenza seasons (2002-06) [57]. Risk of fever and SAEs was examined in 66,283 children ( 91,692 doses). Similar case-crossover analysis showed no SAEs associated 


\begin{tabular}{|c|c|c|c|c|c|c|c|c|}
\hline 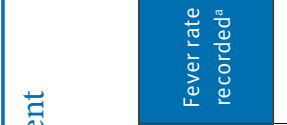 & 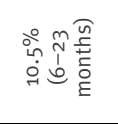 & 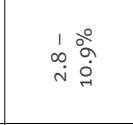 & $\stackrel{\circ}{\circ}$ & 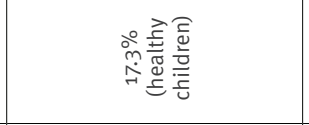 & 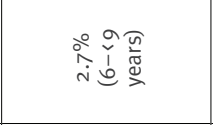 & 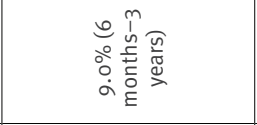 & $\stackrel{\circ}{\stackrel{\circ}{\dot{m}}}$ & 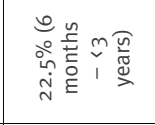 \\
\hline 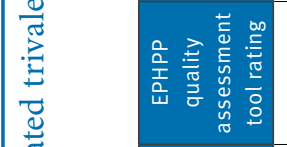 & 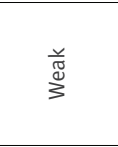 & 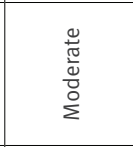 & 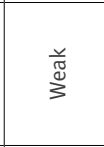 & 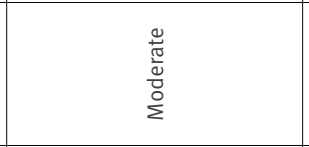 & 嵒 & 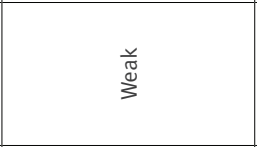 & 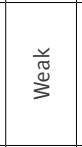 & 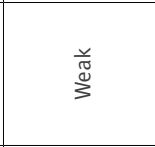 \\
\hline 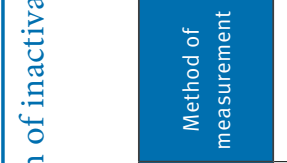 & 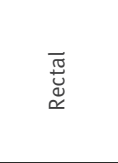 & 宸 & 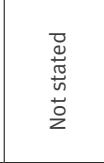 & 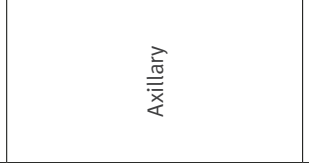 & 蒿 & 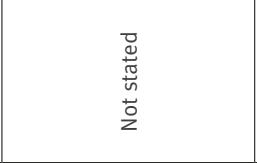 & 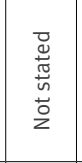 & 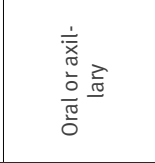 \\
\hline 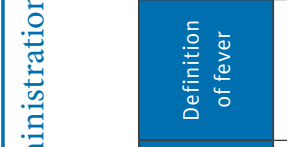 & 峁 & $\underset{\substack{0 \\
\text { o } \\
\text { N }}}{ }$ & 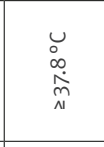 & $\begin{array}{l}\text { O. } \\
\stackrel{N}{N} \\
\text { N }\end{array}$ & $\begin{array}{l}\stackrel{u}{\circ} \\
\stackrel{N}{N} \\
\end{array}$ & $\begin{array}{l}\stackrel{u}{o} \\
\stackrel{\leftrightarrow}{M} \\
N\end{array}$ & 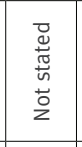 & 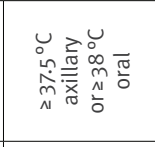 \\
\hline 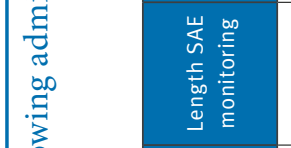 & 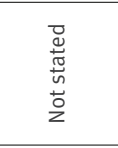 & 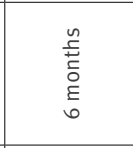 & 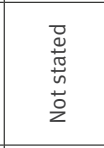 & 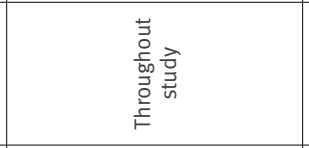 & 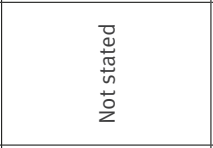 & $\underset{\substack{\tilde{\sigma} \\
m}}{n}$ & 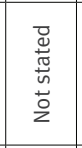 & 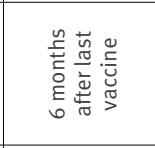 \\
\hline 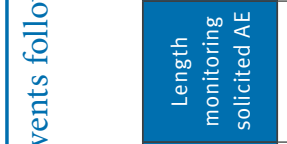 & 誉 & 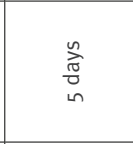 & 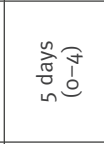 & 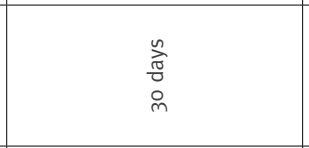 & 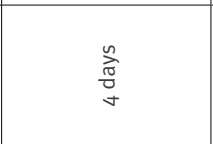 & 嘕 & 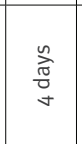 & 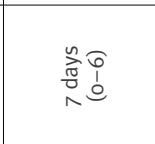 \\
\hline 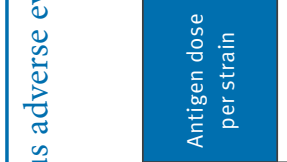 & 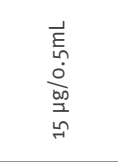 & 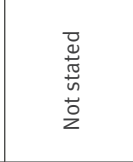 & 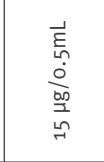 & 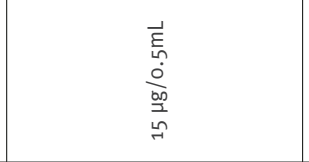 & 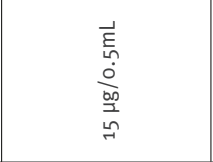 & 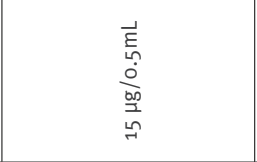 & 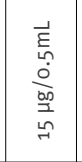 & 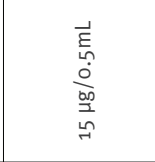 \\
\hline 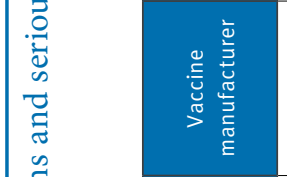 & 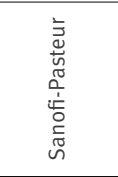 & 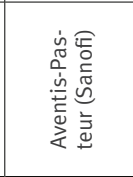 & 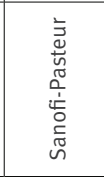 & 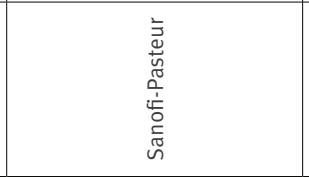 & 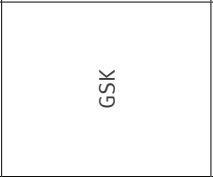 & 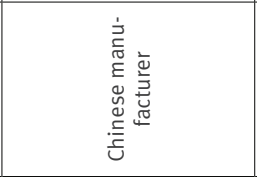 & 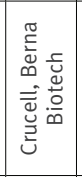 & $\begin{array}{l}\overrightarrow{\breve{U}} \\
\stackrel{\circ}{a}\end{array}$ \\
\hline $\begin{array}{l}0 \\
0 \\
0 \\
0 \\
0 \\
0 \\
0 \\
0 \\
0\end{array}$ & 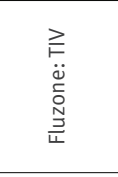 & 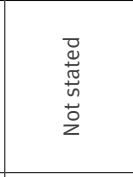 & 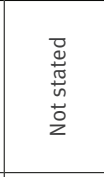 & 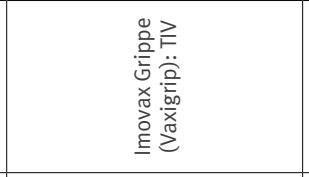 & 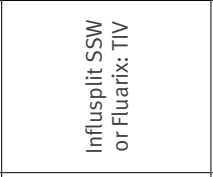 & $\gtreqless$ & 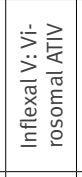 & 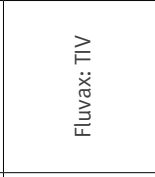 \\
\hline 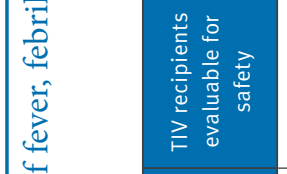 & $\vec{m}$ & $\stackrel{\circ}{\circ}$ & $\tilde{N}$ & $\underset{\sim}{\infty}$ & $\underset{\text { N }}{\mathbb{N}}$ & 兑 & $\stackrel{\stackrel{\leftrightarrow}{\sigma}}{\sigma}$ & $\stackrel{\tilde{N}}{\tilde{N}}$ \\
\hline 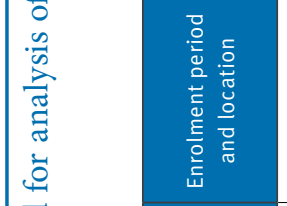 & 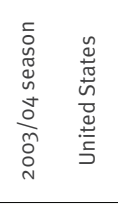 & 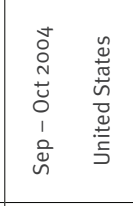 & 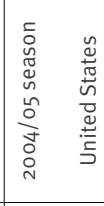 & 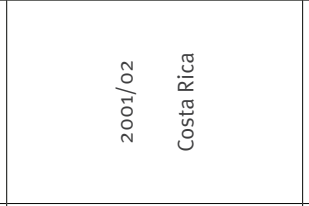 & 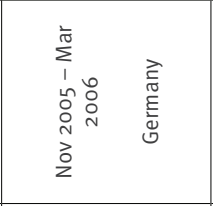 & 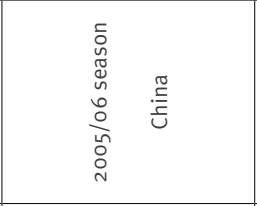 & 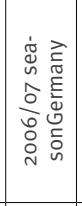 & 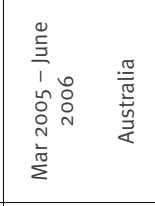 \\
\hline 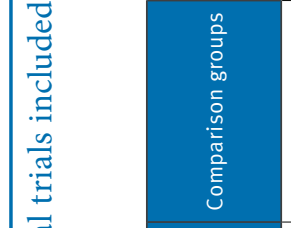 & 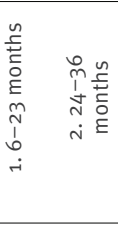 & 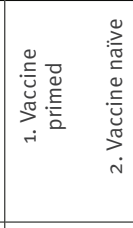 & 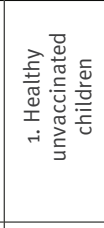 & 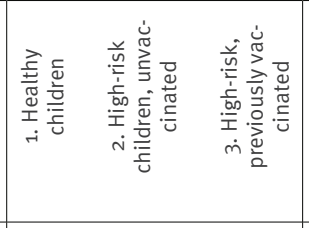 & 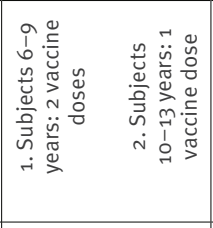 & 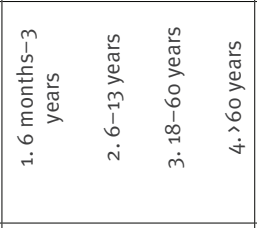 & 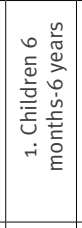 & 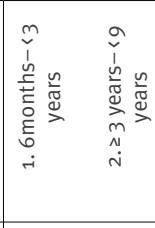 \\
\hline 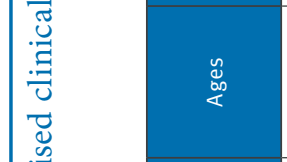 & 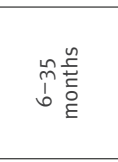 & 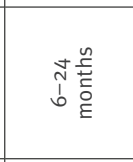 & 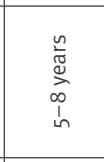 & 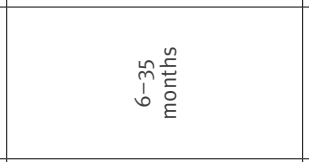 & 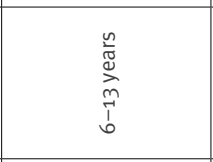 & 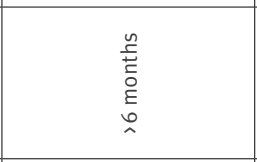 & 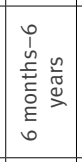 & 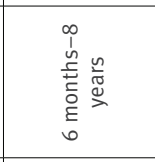 \\
\hline 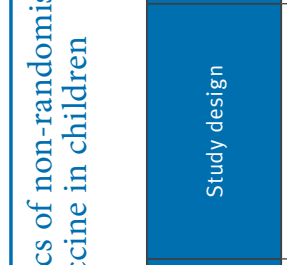 & 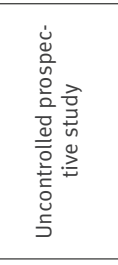 & 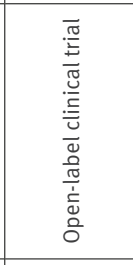 & 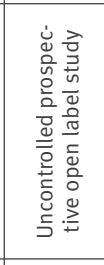 & 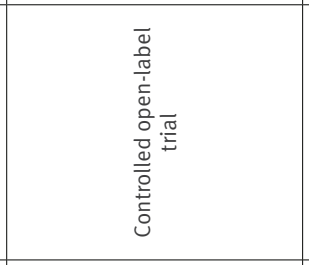 & 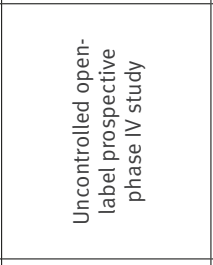 & 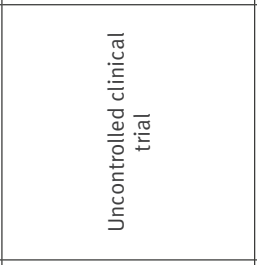 & 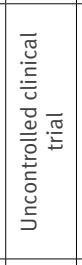 & 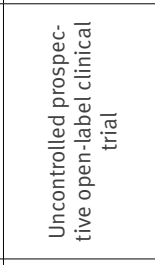 \\
\hline 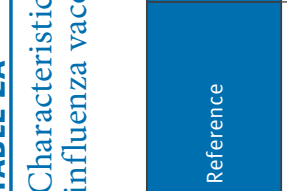 & 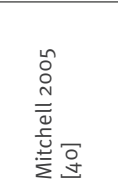 & 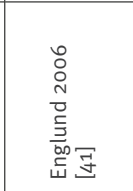 & 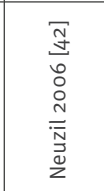 & 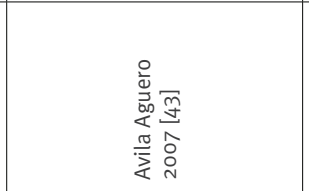 & 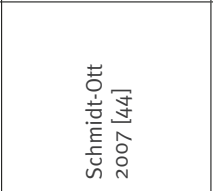 & 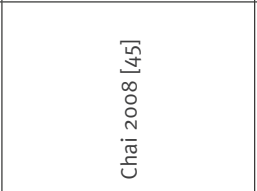 & 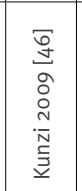 & $\begin{array}{l}\frac{T}{y} \\
o \\
o \\
\text { N } \\
\frac{1}{0} \\
\frac{\pi}{2}\end{array}$ \\
\hline
\end{tabular}




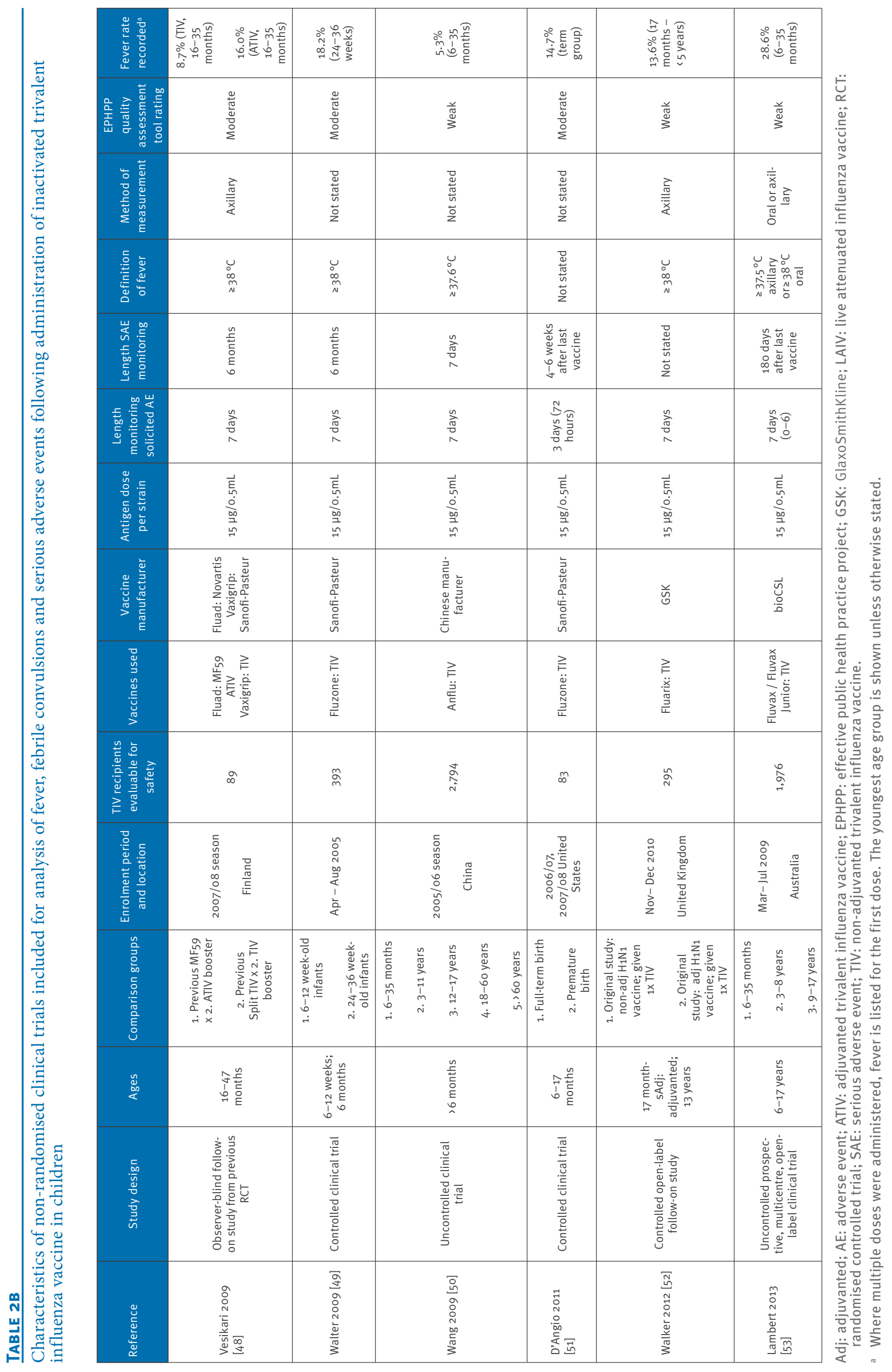




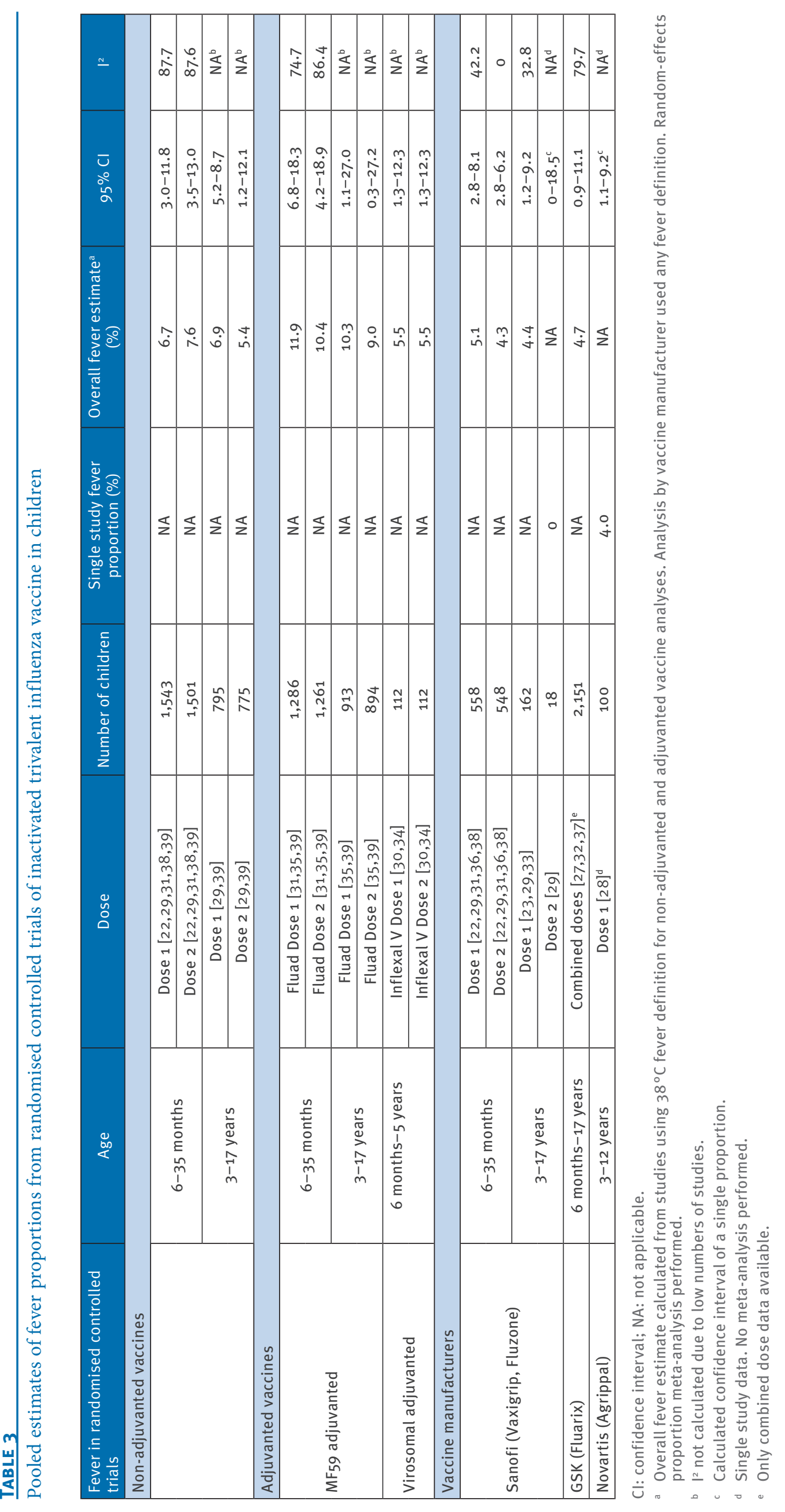




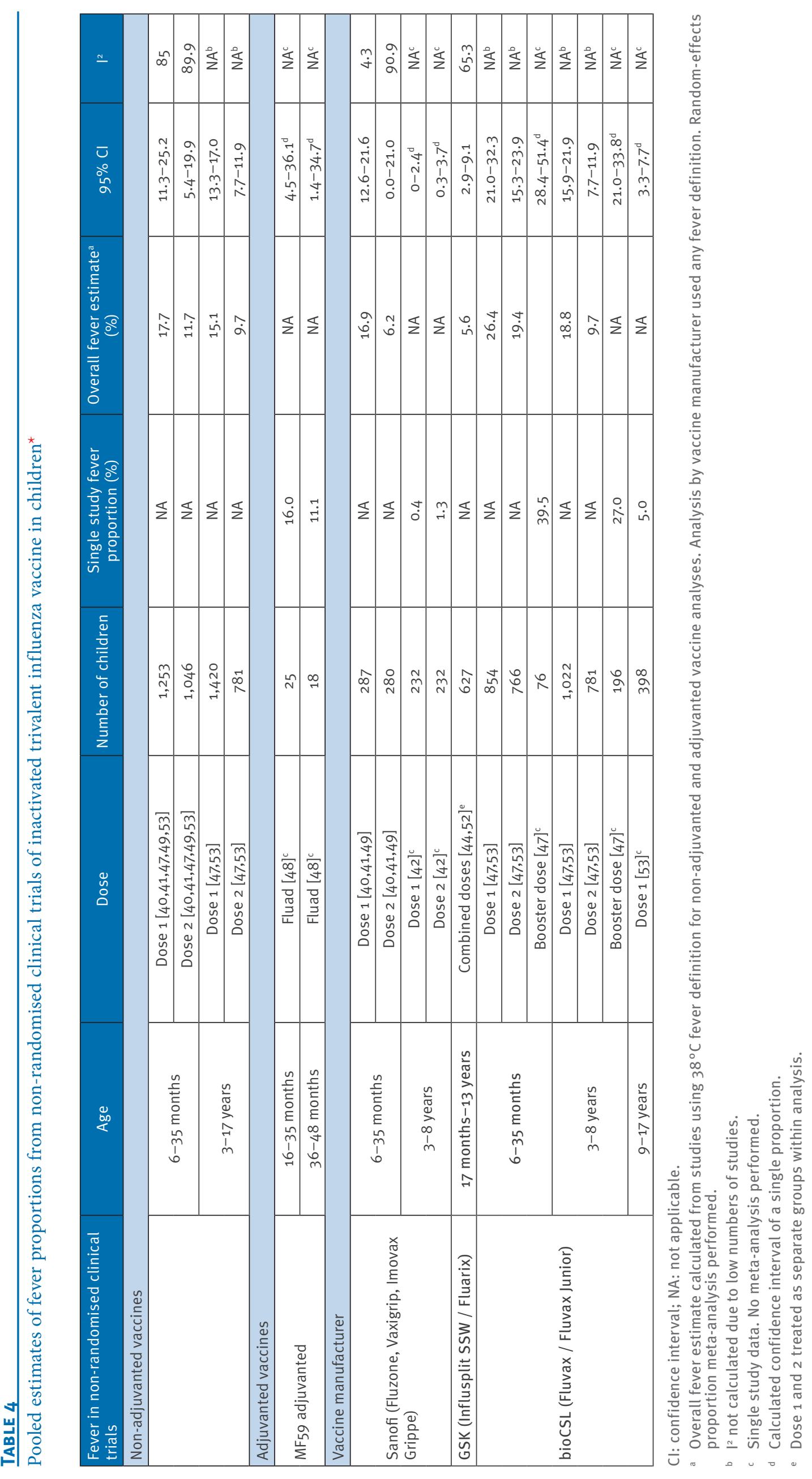




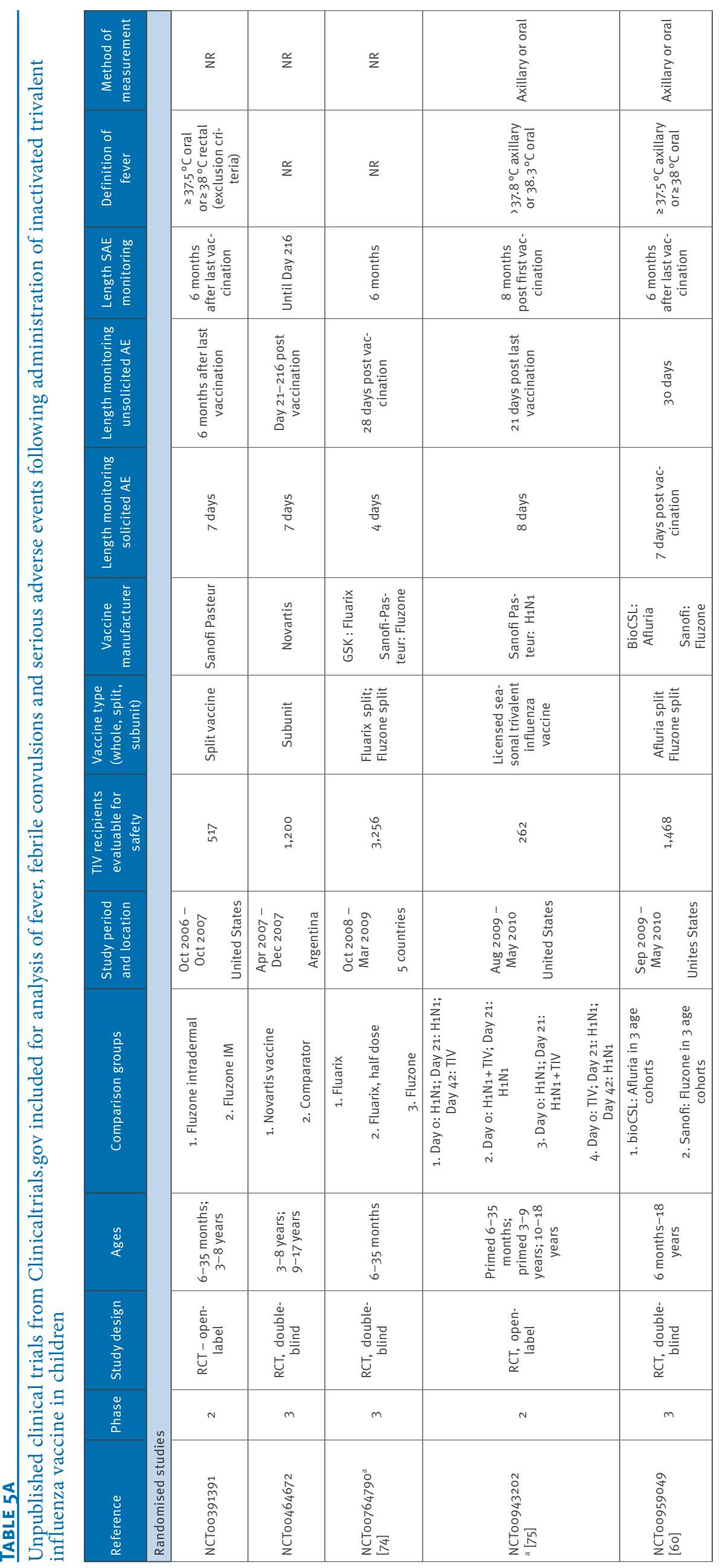




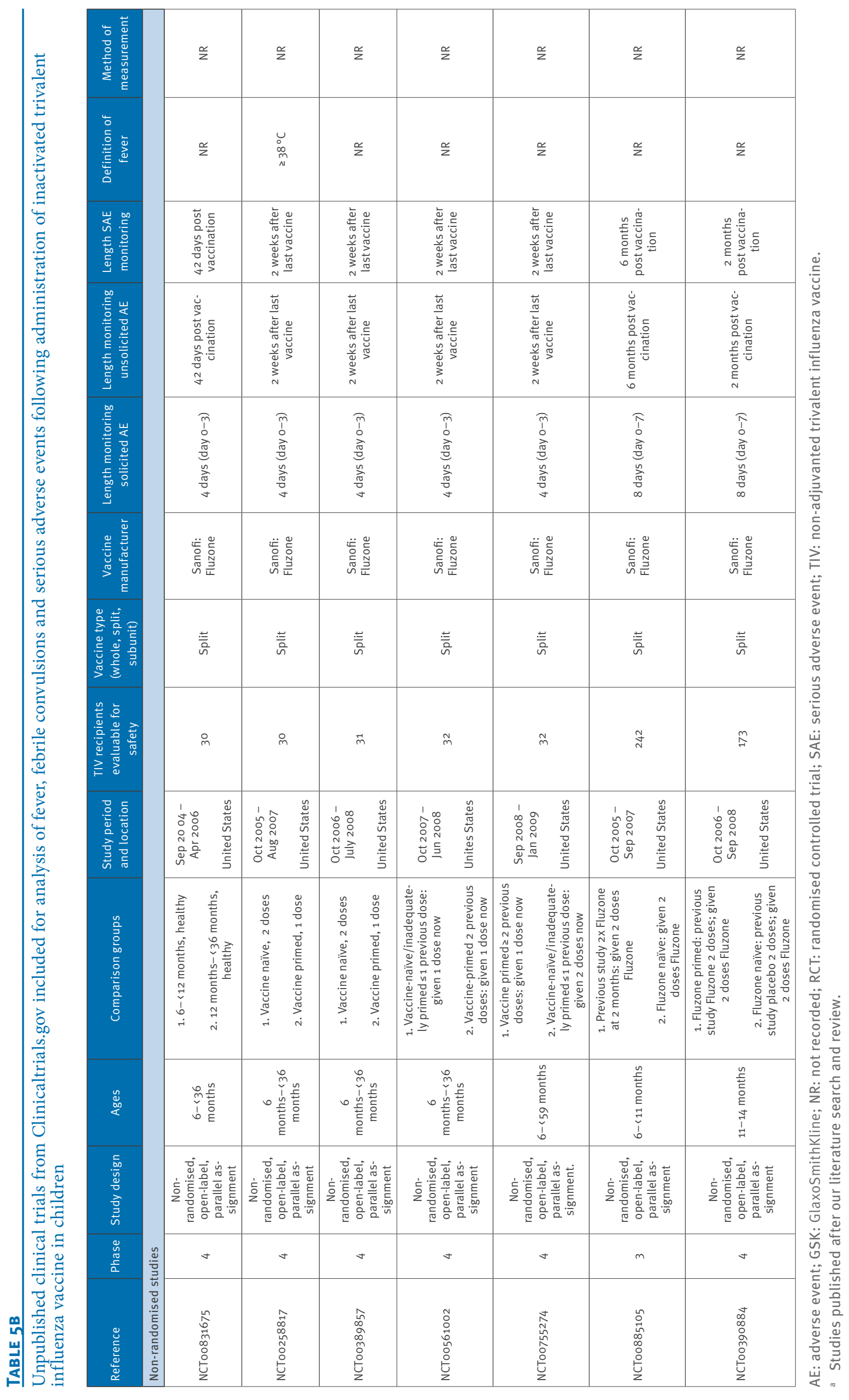


with TIV in healthy children, however, fever was significantly associated with TIV within the window between Day 1 and 14 (incidence rate ratio $($ IRR) $=1.71$; $95 \% \mathrm{Cl}$ : 1.64-1.80).

One retrospective observational cohort study in children in Western Australia (WA) from 2010 reported on the rate of fever seen with bioCSL TIV [58]. Data linkage of TIV-associated FC cases and vaccine exposure recorded in the Australian Childhood Immunisation Register, was added to data obtained from vaccine providers or primary caregivers. A high rate of $\mathrm{FC}$, 3.3 per 1,000 vaccine doses, was documented during the 49-day vaccination programme, with 62 of 63 FC associated with bioCSL TIV, all occurring after a first dose, with a median time of 7 hours from vaccination to symptom onset. In children younger than five years, FCs were significantly more associated with bioCSL TIV than with Solvay's Influvac ( $p<0.0001)$.

Subsequent to the reporting of excess FC rates post TIV in Australia, another VSD study was conducted in the US during the 2010/11 influenza season, examining Day 0 to 1 after TIV administration and examined 206,174 children aged six to 59 months who received at least one dose of vaccine [59]. None received bioCSL vaccine as its recommendation had been removed. While the main finding was of increased FC with concurrent TIV and 13-valent pneumococcal conjugate vaccine (PCV13), adjustment for PCV 13 still yielded a statistically significant increase in seizures following TIV by itself (IRR $=2.4 ; 95 \% \mathrm{Cl}: 1.2-4.7)$. The risk difference estimate was maximal at 16 months of age with 12.5 vaccine-attributable seizures per 100,000 doses.

\section{Discussion}

Our study summarises fever and FC data from multiple clinical trials, reporting group (not individual) safety outcomes following TIV receipt. Using published RCT data, we have found a reassuringly low pooled rate of fever $\geq 38^{\circ} \mathrm{C}$ after non-adjuvanted TIV, which was similar to most non-bioCSL vaccines in observational studies conducted during 2010 when safety concerns arose due to bioCSL TIV [61-63].

Limited pooled data on investigational MF59-ATIV showed higher fever rates compared with non-adjuvanted vaccines. However in the two RCTs $[31,39]$ with direct comparison of MF59-ATIV and TIV, fever rate differences were non-significant between adjuvanted and non-adjuvanted vaccine groups, apart from a subset of children aged 36 to 71 months in one study where the MF59-ATIV recipients had higher fever [39]. The same RCT [39] found no differences in fever rate between MF59-ATIV and TIV in younger children aged six to 35 months. However, it also recorded the highest fever rates in the non-adjuvanted arm for this age group (13.3\% and $13.4 \%$ for doses 1 and 2 , respectively) relative to all other non-adjuvanted vaccine study arms in our meta-analysis; this may have contributed to the absence of observable difference in fever between
MF59-ATIV and TIV. In addition, the European Medicines Agency (EMA) raised concerns, after site inspections, that this study was not conducted in accordance with guidelines on good clinical practice (GCP), and therefore did not grant marketing approval for the Novartis MF59-ATIV used $[64,65]$.

Non-randomised clinical trials were of lower quality, often being uncontrolled. Pooled fever estimates for non-adjuvanted vaccines were higher than those from RCTs, probably due in part to the inclusion of reactogenic bioCSL vaccines $[47,53]$, although other manufacturers' vaccines also recorded higher fever rates than in RCT studies.

A recent systematic review of fever by Kaczmarek et al. following dose 1 of inactivated TIV, reported a similar rate $(8.0 \%)$ for any fever in children aged six to $<36$ months after non-adjuvanted TIV, using weighted average weekly risk [66]. However, our study, by using a proportion meta-analysis method, allowed inclusion of a broader range of studies. We used the Brighton Collaboration's fever definitions $\left(\geq 38^{\circ} \mathrm{C}\right)$ and analysed fever in a number of additional settings: adjuvanted vaccine studies, older children (36 months and older), fever after second doses of vaccine and by vaccine manufacturer.

Most non-bioCSL brand TIVs had low rates of fever in RCT analyses. However, bioCSL TIVs had significantly higher fever after first doses in children aged six months to eight years, across three studies conducted from March 2005 through to May 2010, particularly in an RCT (NCToo959049) comparing bioCSL's Afluria and a comparator TIV [6o], subsequently published after our literature search and review (Table 6). Observational studies from 2010 in Australia and New Zealand documented similar findings comparing bioCSL TIV to other manufacturers [58,62].

Our findings on SAE and FC rates are considerably limited by the absence of studies using within-study placebo controls, which precludes calculation of true vaccination-related rates. However, analysing TIVvaccinated arms, we found that vaccination-related SAEs were uncommon. Our calculated FC rate from published RCT data (no bioCSL studies available) was 1.1 per 1,000 children six to $<72$ months-old and vaccinated with non-adjuvanted TIV. However, it was unclear in one study if all FC reported were causally related to TIV [39]; the actual rate may be lower. The same study showed no difference in FC rates between TIV and the non-TIV, active control arm [39]. We could not calculate $\mathrm{FC}$ rates in the clinical trials with bioCSL vaccine, but two observational studies conducted since 2010 reported FC rates of 3.5-4.4/1,000 doses for bioCSL Fluvax/Fluvax Junior compared with no FCs after 4,720 doses of Solvay vaccine (Influvac) or 3,213 doses of non-bioCSL TIV [58,62]. Furthermore, a 2010 investigation by the Therapeutics Goods Administration (TGA) 
TABLE 6

Fever estimates from unpublished trials identified at Clinicaltrials.gov following administration of inactivated trivalent influenza vaccine in children

\begin{tabular}{|c|c|c|c|c|c|}
\hline Study code & Fever definition & Age & Dose & $\begin{array}{l}\text { Fever rate study vaccine } \\
\% \text { (denominator) }\end{array}$ & $\begin{array}{c}\text { Fever rate comparator vaccine } \\
\% \text { (denominator) }\end{array}$ \\
\hline \multicolumn{6}{|c|}{ Randomised controlled trials } \\
\hline \multirow{5}{*}{ NCTo0391391 } & \multirow{5}{*}{$>37.5^{\circ} \mathrm{C}$} & & & Fluzone intramuscular & Fluzone intradermal \\
\hline & & $6-35$ months & Dose 1 & $10.3 \%(97)$ & $10.3 \%(97)$ \\
\hline & & $6-35$ months & Dose 2 & $9.3 \%(97)$ & $6.2 \%(97)$ \\
\hline & & 3-8 years & Dose 1 & $11.0 \%(163)$ & $6.3 \%(160)$ \\
\hline & & $3-8$ years & Dose 2 & $8.6 \%(163)$ & $10.0 \%(160)$ \\
\hline \multirow{4}{*}{ NCTo 464672} & \multirow{4}{*}{ ND } & & & Novartis vaccine & Comparator vaccine \\
\hline & & $3-8$ years & Dose 1 & $3.0 \%(402)$ & $1.5 \%(199)$ \\
\hline & & $3-8$ years & Dose 2 & $2.5 \%(396)$ & $2.5 \%(197)$ \\
\hline & & 9-17 years & Dose 1 & $0.3 \%(400)$ & $2.0 \%(199)$ \\
\hline \multirow{2}{*}{ NCToo $764790^{b}$} & \multirow{2}{*}{ ND } & & & Fluarix - GSK & Fluzone - Sanofi Pasteur \\
\hline & & $6-35$ months & Any dose & $6.2 \%(1,080)$ & $6.6 \%(1090)$ \\
\hline \multirow{4}{*}{ NCToog $43202^{c}$} & \multirow{4}{*}{$\geq 37.8^{\circ} \mathrm{C}$} & & & TIV as first vaccine & TIV as third vaccine \\
\hline & & $6-35$ months & Fever after TIV & $10.7 \%(28)$ & $9.4 \%(32)$ \\
\hline & & $3-9$ years & Fever after TIV & $2.0 \%(51)$ & $0.0 \%(49)$ \\
\hline & & $10-17$ years & Fever after TIV & $3.8 \%(53)$ & $0.0 \%(49)$ \\
\hline \multirow{6}{*}{ NCToo959049[60] } & \multirow{6}{*}{$\begin{array}{l}\geq 37.5^{\circ} \mathrm{C} \text { axillary } \\
\text { or } \geq 38^{\circ} \mathrm{C} \text { oral }\end{array}$} & & & Afluria-BioCSL & Fluzone - Sanofi \\
\hline & & $6-35$ months & Dose 1 & $37.1 \%(229)$ & $13.6 \%(228)$ \\
\hline & & $6-35$ months & Dose 2 & $14.6 \%(96)$ & $13.6 \%(110)$ \\
\hline & & 3-8 years & Dose 1 & $21.8 \%(252)$ & $9.4 \%(255)$ \\
\hline & & $3-8$ years & Dose 2 & $5.9 \%(68)$ & $6.4 \%(78)$ \\
\hline & & 9-17 years & Dose 1 & $6.3 \%(254)$ & $4.0 \%(250)$ \\
\hline \multicolumn{6}{|c|}{ Non randomised studies } \\
\hline \multirow{4}{*}{ NCToo 831675} & \multirow{4}{*}{ ND } & 6-11 months & Dose 1 & $0.0 \%(12)$ & \\
\hline & & 6-11 months & Dose 2 & $8.3 \%(12)$ & \\
\hline & & 12-35 months & Dose 1 & $16.7 \%(18)$ & \\
\hline & & $12-35$ months & Dose 2 & $16.7 \%(18)$ & \\
\hline \multirow{3}{*}{ NCTo0258817 } & \multirow{3}{*}{$\geq 38^{\circ} \mathrm{C}$} & & & Vaccine naïve & Vaccine primed \\
\hline & & $6-35$ months & Dose 1 & $6.7 \%(15)$ & $13.3 \%(15)$ \\
\hline & & $6-35$ months & Dose 2 & $33.3 \%(15)$ & \\
\hline \multirow{3}{*}{ NCTo0389857 } & \multirow{3}{*}{ ND } & & & Vaccine naïve & Vaccine primed \\
\hline & & $6-35$ months & Dose 1 & $0.0 \%(14)$ & $5.9 \%(17)$ \\
\hline & & $6-35$ months & Dose 2 & $7.1 \%(14)$ & \\
\hline \multirow{3}{*}{ NCTo0 561002} & \multirow{3}{*}{ ND } & & & Vaccine naïve & Vaccine primed \\
\hline & & $6-35$ months & Dose 1 & $17.4 \%(23)$ & $22.2 \%(9)$ \\
\hline & & $6-35$ months & Dose 2 & $13.0 \%(23)$ & \\
\hline \multirow{3}{*}{ NCTo0755274 } & \multirow{3}{*}{ ND } & & & Vaccine naïve & Vaccine primed \\
\hline & & $6-59$ months & Dose 1 & $25.0 \%(8)$ & $8.3 \%(24)$ \\
\hline & & $6-59$ months & Dose 2 & $25.0 \%(8)$ & \\
\hline \multirow{3}{*}{ NCToo885105 } & & & & Fluzone (Sanofi) naïve & Fluzone (Sanofi) primed \\
\hline & ND & $6-10$ months & Dose 1 & $25.0 \%(130)$ & $25.0 \%(112)$ \\
\hline & & $6-10$ months & Dose 2 & $14.0 \%(130)$ & $14.0 \%(112)$ \\
\hline & & & & Fluzone (Sanofi) naïve & Fluzone (Sanofi) primed \\
\hline NCTo0390884 & ND & 11-14 months & Dose 1 & $10.5 \%(57)$ & $15.5 \%(116)$ \\
\hline & & 11-14 months & Dose 2 & $15.8 \%(57)$ & $17.2 \%(116)$ \\
\hline
\end{tabular}

ND: not defined; TIV: trivalent influenza vaccine.

a Only data on intramuscularly administered vaccine group was used.

b Only groups with full dose were examined. Data from groups with half dose are not presented.

c Only groups with TIV administered alone are listed. 


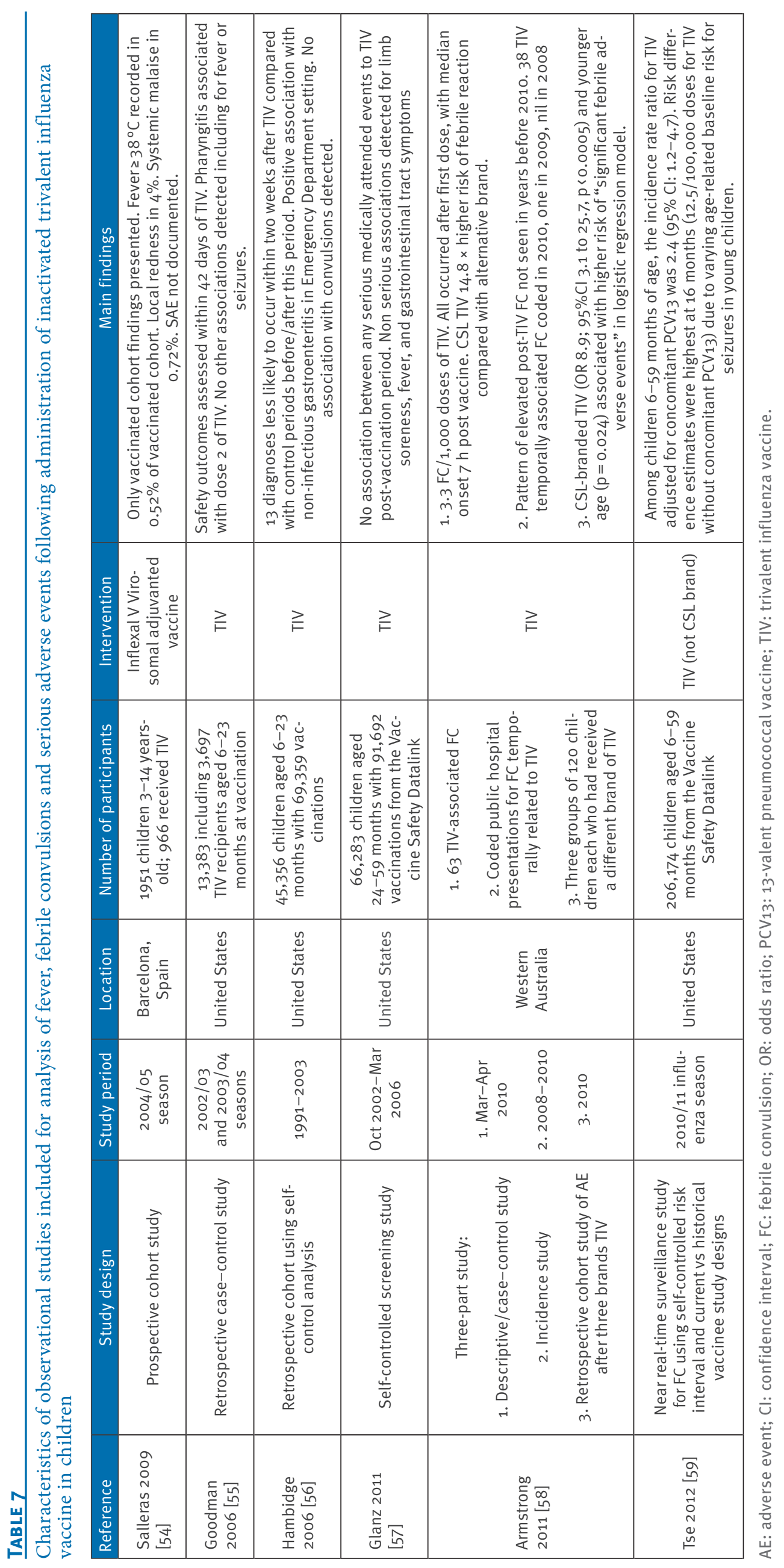


into bioCSL vaccine found FC rates of $5^{-7}$ per 1,000 doses [9].

Based on one study, MF59-ATIV was associated with 2.59 FCs per 1,000 vaccinated children aged six to 71 months, but this was not significantly different to control groups (non-adjuvanted TIV or active control vaccine) [39]. Further study of adjuvanted vaccines is warranted to investigate their safety profile, in terms of fever and FC.

Despite an observational study reporting a link between the 2010/11 US non-bioCSL TIV and FC on Day 0 to 1 [59] (mostly with concurrent PCV13), the absolute risk of TIV-related FC appeared low overall (a maximum of 12.5/100,000 doses), less than the risk seen after measles-mumps-rubella (MMR) vaccine $(33 / 100,000)$ and similar to the risk after 13 -valent PCV $(13.7 / 100,000)$ [59,67]. A subsequent study of the 2011/12 US influenza season confirmed elevated fever after concurrent TIV and PCV13 on Day o to 1 and listed fever rates after TIV alone similar to our findings at $7.5 \%$ in children aged six to 23 months [68].

Proposed explanations for higher fever rates with bioCSL vaccines have included 2010 TIV strain changes and manufacturing methods. Investigations by bioCSL concluded that their method of manufacture retained more virus components due to less splitting of virus, compared with other manufacturers, and that characteristics of the three viruses included in the 2010 vaccine elicited an excessive immune response in young children $[69,70]$. However, all manufacturers used the same new strains in formulating the 2010 southern hemisphere vaccine without eliciting increased fever or FCs.

These results highlight the differences in the propensity to febrile events that may exist between different companies' TIVs. The single RCT (NCTo0959049) comparing bioCSL TIV with a comparator vaccine in children most clearly demonstrates these important differences. This study was conducted in $2009 / 10$ but only recently published in 2014 [6o]. It was not yet completed when the bioCSL TIV problem emerged in April 2010. Access to individual level data of this study would offer valuable insights into fever following receipt of TIV.

The lack of clearly presented, publicly available, comparable data regarding the safety of influenza vaccines, particularly in young children, has been emphasised in a previous systematic review of influenza vaccination [71]. Few of the studies we examined were eligible for that systematic review due to the lack of placebo controls. Without such placebo-controlled studies, the true rate of adverse events due solely to TIV is difficult to ascertain accurately. Such studies are difficult to justify ethically as more and more countries recommend universal influenza vaccination of healthy children. Our study addressed as much data as possible, with sensitivity analyses, to provide the most comprehensive information by which to compare vaccines.

Limitations of this study are acknowledged, including the difficulty of comparing studies that have different methodology. By examining studies involving healthy children, we have maximised the comparability of studies, but the findings may not apply to children with chronic illness for whom TIV is specifically recommended. The majority of fever analyses showed substantial heterogeneity; I2 values ranged from $0 \%$ to $95.6 \%$ with most beinglarger than $50 \%$. Bias assessment revealed that the majority of randomised studies had low to moderate risk of bias. A randomeffects model for pooled fever estimates was used to provide an accurate estimate across variable studies. Our sensitivity analysis was not able to identify specific sources of heterogeneity based on assessments of study quality, but underlying study variability is the most likely cause.

Our analysis did not specifically take into account differing follow-up periods. Solicited AE follow-up periods longer than 48 hours result in the possibility of unrelated fever being captured. This highlights the need for consistent reporting in studies of post-vaccination fever rates occurring within specific timeframes, particularly the first 24 hours. Lastly, most pooled fever estimates involved overlapping confidence intervals, meaning that the point estimates of fever must be compared cautiously. However, where possible, we have compared similar types of vaccines, within set age ranges, and included studies that used Brighton Collaboration definitions of fever.

\section{Conclusions and recommendations}

This review provides a generally reassuring assessment on the safety of most TIVs which have low rates of fever or serious adverse events. There is, however, evidence that the bioCSL brand vaccines have been associated with higher rates of fever than comparable vaccines. This cannot be ascribed to the change in vaccine strains alone as the 2010 TIV made by other manufacturers was not highly reactogenic.

Although Tse et al. [59] found an association between early post-vaccination FCs and US 2010/11 non-bioCSL TIVs, containing strains identical to the 2010 southern hemisphere TIV, the risk was low and comparable to other routine immunisations.

We advocate prompt reporting and publication of clinical trial safety data for influenza vaccines. This is even more pertinent with the impending adoption of quadrivalent influenza vaccines (QIV) containing an additional influenza B strain, to ensure that reactogenicity is not increased. Closer scrutiny of the safety of each new season's vaccine formulations in children, for example through a period of active surveillance after TIV release each season, may facilitate the early detection and rapid response to any future safety signals 
to minimise future impacts on the health of vaccinees and maintain confidence in immunisation programmes. The EMA is heading in this direction with requirements from 2014 to 2015 for vaccine manufacturers to implement systems for yearly enhanced safety surveillance to rapidly detect clinically significant changes in the frequency or severity of expected reactogenicity of influenza vaccines $[72,73]$.

Furthermore, we believe public availability of individual-level data (of precise levels of fever over time) from both past and future vaccine trials as well as the use of standardised study methods, through stricter adherence to Brighton Collaboration case definitions and reporting recommendations for adverse events, is essential to enable effective comparison both between vaccines and over time.

\section{Erratum *}

The statement of conflict of interest was omitted in the original publication and added on 25 June 2015. In Table 4, a line was added between the data for GSK and BioCSL.

\section{Conflict of interest *}

J. K. Yin received an educational grant from Sanofi Pasteur for influenza economic research in 2012. R. Booy has received funding from bioCSL, Roche, Sanofi, GlaxoSmithKline (GSK), Novartis, and Pfizer to conduct sponsored research or attend and present at scientific meetings; any funding received is directed to a research account at the Children's Hospital at Westmead. C. Jones has received funding from GlaxoSmithKline (GSK) to attend and present at the New Zealand Infection and Immunisation Special Interest group in 2013.

\section{Authors' contributions}

Jean Li-Kim-Moy conceived and designed the study, was involved in screening of relevant studies, data collection, data analysis, data interpretation and writing of the manuscript. Jiehui Kevin Yin conceived and designed the study, was involved in screening of relevant studies, data collection, assisted in writing all sections of the paper, and revision of the manuscript. Harunor Rashid conceived and designed the study, was involved in screening of relevant studies, data collection, data analysis, and revision of the manuscript. Gulam Khandaker assisted with design of the study, was involved in screening of relevant studies, and revised the manuscript. Catherine King conducted the electronic literature search, assisted in writing the methods section, and revised the manuscript. Nicholas Wood, Kristine Macartney, and Cheryl Jones revised the manuscript and assisted in writing all sections of the manuscript. Robert Booy conceived, designed, and supervised the study; he was involved in data interpretation, writing of all sections of the paper, and revision of the manuscript.

\section{References}

1. Poehling KA, Edwards KM, Weinberg GA, Szilagyi P, Staat MA, Iwane MK, et al.; New Vaccine Surveillance Network. The underrecognized burden of influenza in young children. N Engl J Med. 2006;355(1):31-40. http://dx.doi.org/10.1056/ NEJMoa054869 PMID:16822994
2. Neuzil KM, Zhu Y, Griffin MR, Edwards KM, Thompson JM, Tollefson SJ, et al. Burden of interpandemic influenza in children younger than 5 years: a 25 -year prospective study. J Infect Dis. 2002;185(2):147-52. http://dx.doi. org/10.1086/338363 PMID:11807687

3. Sakkou Z, Stripeli F, Papadopoulos NG, Critselis E, Georgiou V, Mavrikou M, et al. Impact of influenza infection on children's hospital admissions during two seasons in Athens, Greece. Vaccine. 2011;29(6):1167-72. http://dx.doi.org/10.1016/j. vaccine.2010.12.014 PMID:21172380

4. Thompson WW, Shay DK, Weintraub E, Brammer L, Bridges CB, Cox NJ, et al. Influenza-associated hospitalizations in the United States. JAMA. 2004;292(11):1333-40. http://dx.doi. org/10.1001/jama.292.11.1333 PMID:15367555

5. Advisory Committee on Immunization Practices (ACIP). Summary recommendations: Prevention and control of influenza with vaccines: Recommendations of the Advisory Committee on Immunization Practices-(ACIP)-United States, 2013-14. Atlanta: Centers for Disease Control and Prevention; 2013. Available from: http://www.cdc.gov/flu/professionals/ acip/2013-summary-recommendations.htm

6. Mereckiene J, Cotter S, D’Ancona F, Giambi C, Nicoll A, LevyBruhl D, et al. Differences in national influenza vaccination policies across the European Union, Norway and Iceland 20082009. Euro Surveill. 2010;15(44):19700. PMID:21087586

7. The flu immunisation programme $2013 / 14$ - extension to children. London: Department of Health; 2013. Available from: https://www.gov.uk/government/uploads/system/uploads/ attachment_data/file/225360/Children_s_flu_letter_2013.pdf

8. Flu (influenza) vaccine and children: what WA parents need to know. Perth: Department of Health Western Australia. [Accessed: Nov 2012]. Available from: http://www.health. wa.gov.au/flu/families_individuals/children.cfm

9. Therapeutic Goods Administration (TGA). Seasonal flu vaccine: Overview of vaccine regulation and safety monitoring and investigation into adverse events following 2010 seasonal influenza vaccination in young children. Canberra: TGA; 2010. Available from: https://www.tga.gov.au/alert/ seasonal-flu-vaccine-overview-vaccine-regulation-and-safetymonitoring-and-investigation-adverse-events-following-2010seasonal-influenza-vaccination-young-children

10. Mak DB, Carcione D, Joyce S, Tomlin S, Effler PV. Paediatric influenza vaccination program suspension: effect on childhood vaccine uptake. Aust N Z J Public Health. 2012;36(5):4945. http://dx.doi.org/10.1111/j.1753-6405.2012.00925.x PMID:23025380

11. Marcy SM, Kohl KS, Dagan R, Nalin D, Blum M, Jones MC, et al. Fever as an adverse event following immunization: case definition and guidelines of data collection, analysis, and presentation. Vaccine. 2004;22(5-6):551-6. http://dx.doi. org/10.1016/j.vaccine.2003.09.007 PMID:14741143

12. US Food and Drug Administration (FDA). What is a serious adverse event? Silver Spring: FDA. [Accessed: Sep 2014]. Available from: http://www.fda.gov/safety/medwatch/ howtoreport/ucm053087.htm

13. Altmann M, Fiebig L, Soyka J, von Kries R, Dehnert M, Haas W. Severe cases of pandemic $\left(\mathrm{H}_{1} \mathrm{~N}_{1}\right) 2009$ in children, Germany. Emerg Infect Dis. 2011;17(2):186-92. http://dx.doi.org/10.3201/ eid1702.101090 PMID:21291587

14. Effective Public Health Practice Project (EPHPP). Quality assessment tool for quantitative studies. Hamilton: EPHPP. [Accessed: Oct 2013]. Available from: http://www.ephpp.ca/ tools.html

15. Deeks JJ, Dinnes J, D’Amico R, Sowden AJ, Sakarovitch C, Song $\mathrm{F}$, et al. Evaluating non-randomised intervention studies. Health Technol Assess. 2003;7(27):iii-x, 1-173. http://dx.doi. org/10.3310/hta7270 PMID:14499048

16. Yin JK, Khandaker G, Rashid H, Heron L, Ridda I, Booy R. Immunogenicity and safety of pandemic influenza $A\left(\mathrm{H}_{1} \mathrm{~N}_{1}\right)$ 2009 vaccine: systematic review and meta-analysis. Influenza Other Respi Viruses. 2011;5(5):299-305. http://dx.doi. org/10.1111/j.1750-2659.2011.00229.x PMID:21668694

17. Agarwal R, Aggarwal AN, Gupta D. Role of noninvasive ventilation in acute lung injury/acute respiratory distress syndrome: a proportion meta-analysis. Respir Care. 2010;55(12):1653-60. PMID:21122173

18. Mitchell AJ, Chan M, Bhatti H, Halton M, Grassi L, Johansen $C$, et al. Prevalence of depression, anxiety, and adjustment disorder in oncological, haematological, and palliative-care settings: a meta-analysis of 94 interview-based studies. Lancet Oncol. 2011;12(2):160-74. http://dx.doi.org/10.1016/ S1470-2045(11)70002-X PMID:21251875

19. Mills EJ, Nachega JB, Buchan I, Orbinski J, Attaran A, Singh S, et al. Adherence to antiretroviral therapy in sub-Saharan Africa and North America: a meta-analysis. JAMA. 2006;296(6):67990. http://dx.doi.org/10.1001/jama.296.6.679 PMID:16896111 
20. Pal T, Permuth-Wey J, Kumar A, Sellers TA. Systematic review and meta-analysis of ovarian cancers: estimation of microsatellite-high frequency and characterization of mismatch repair deficient tumor histology. Clin Cancer Res. 2008;14(21):6847-54. http://dx.doi.org/10.1158/1078-0432. CCR-08-1387 PMID:18980979

21. Stasi R, Sarpatwari A, Segal JB, Osborn J, Evangelista ML, Cooper N, et al. Effects of eradication of Helicobacter pylori infection in patients with immune thrombocytopenic purpura: a systematic review. Blood. 2009;113(6):1231-40. http://dx.doi. org/10.1182/blood-2008-07-167155 PMID:18945961

22. Englund JA, Walter EB, Fairchok MP, Monto AS, Neuzil KM. A comparison of 2 influenza vaccine schedules in 6- to 23-month-old children. Pediatrics. 2005;115(4):1039-47. http:// dx.doi.org/10.1542/peds.2004-2373 PMID:15805382

23. Hu YM, Fang HH, Gao GH, Zhang XF, Zhang YJ, Zhu SW, et al. [Evaluation on the safety and immunogenicity of Canada split influenza virus vaccine]. Zhonghua Liu Xing Bing Xue Za Zhi. 2005;26(7):503-6. Chinese. PMID:16335001

24. Ashkenazi S, Vertruyen A, Arístegui J, Esposito S, McKeith DD, Klemola T, et al. Superior relative efficacy of live attenuated influenza vaccine compared with inactivated influenza vaccine in young children with recurrent respiratory tract infections. Pediatr Infect Dis J. 2006;25(10):870-9. http://dx.doi. org/10.1097/01.inf.0000237829.66310.85 PMID:17006279

25. Walter EB, Neuzil KM, Zhu Y, Fairchok MP, Gagliano ME, Monto $A S$, et al. Influenza vaccine immunogenicity in 6- to 23-monthold children: are identical antigens necessary for priming? Pediatrics. 2006;118(3):e570-8. http://dx.doi.org/10.1542/ peds.2006-0198 PMID:16950948

26. Belshe RB, Edwards KM, Vesikari T, Black SV, Walker RE, Hultquist M, et al.; CAIV-T Comparative Efficacy Study Group. Live attenuated versus inactivated influenza vaccine in infants and young children. N Engl J Med. 2007;356(7):685-96. http:// dx.doi.org/10.1056/NEJMoa065368 PMID:17301299

27. Chiu SS, Peiris JS, Chan KH, Wong WH, Lau YL. Immunogenicity and safety of intradermal influenza immunization at a reduced dose in healthy children. Pediatrics. 2007;119(6):1076-82. http://dx.doi.org/10.1542/peds.2006-3176 PMID:17545373

28. Zhu FC, Zhou W, Pan H, Lu L, Gerez L, Nauta J, et al. Safety and immunogenicity of two subunit influenza vaccines in healthy children, adults and the elderly: a randomized controlled trial in China. Vaccine. 2008;26(35):4579-84. http://dx.doi. org/10.1016/j.vaccine.2008.05.082 PMID:18602729

29. King JC Jr, Cox MM, Reisinger K, Hedrick J, Graham I, Patriarca P. Evaluation of the safety, reactogenicity and immunogenicity of FluBlok trivalent recombinant baculovirusexpressed hemagglutinin influenza vaccine administered intramuscularly to healthy children aged 6-59 months. Vaccine. 2009;27(47):6589-94. http://dx.doi.org/10.1016/j. vaccine.2009.08.032 PMID:19716456

30. Marchisio P, Esposito S, Bianchini S, Dusi E, Fusi M, Nazzari $E$, et al. Efficacy of injectable trivalent virosomal-adjuvanted inactivated influenza vaccine in preventing acute otitis media in children with recurrent complicated or noncomplicated acute otitis media. Pediatr Infect Dis J. 2009;28(10):855-9. http:// dx.doi.org/10.1097/INF.ob013e3181a487b4 PMID:19564812

31. Vesikari T, Pellegrini M, Karvonen A, Groth N, Borkowski A, O'Hagan DT, et al. Enhanced immunogenicity of seasonal influenza vaccines in young children using MF59 adjuvant. Pediatr Infect Dis J. 2009;28(7):563-71. http://dx.doi org/10.1097/INF.ob013e31819d6394 PMID:19561422

32. Baxter R, Jeanfreau R, Block SL, Blatter M, Pichichero M, Jain VK, et al. A Phase III evaluation of immunogenicity and safety of two trivalent inactivated seasonal influenza vaccines in US children. Pediatr Infect Dis J. 2010;29(10):924-30. http://dx.doi. org/10.1097/INF.obo13e3181e075be PMID:20431425

33. Cowling BJ, Ng S, Ma ESK, Cheng CKY, Wai W, Fang VJ, et al. Protective efficacy of seasonal influenza vaccination against seasonal and pandemic influenza virus infection during 2009 in Hong Kong. Clin Infect Dis. 2010;51(12):1370-9. http://dx.doi. org/10.1086/657311 PMID:21067351

34. Esposito S, Marchisio P, Ansaldi F, Bianchini S, Pacei M, Bagg $E$, et al. A randomized clinical trial assessing immunogenicity and safety of a double dose of virosomal-adjuvanted influenza vaccine administered to unprimed children aged 6-35 months. Vaccine. 2010;28(38):6137-44. http://dx.doi.org/10.1016/j. vaccine.2010.07.041 PMID:20670909

35. Vesikari T, Karvonen A, Tilman S, Borkowski A, Montomoli E, Banzhoff A, et al. Immunogenicity and safety of MF59adjuvanted $\mathrm{H}_{5} \mathrm{~N}_{1}$ influenza vaccine from infancy to adolescence. Pediatrics. 2010;126(4):e762-70. http://dx.doi. org/10.1542/peds.2009-2628 PMID:20819892

36. Hoft DF, Babusis E, Worku S, Spencer CT, Lottenbach K, Truscott SM, et al. Live and inactivated influenza vaccines induce similar humoral responses, but only live vaccines induce diverse T-cell responses in young children. J Infect Dis.
2011;204(6):845-53. http://dx.doi.org/10.1093/infdis/jir436 PMID:21846636

37. Kang JH, Oh CE, Lee J, Lee SY, Cha SH, Kim DS, et al. Safety and immunogenicity of a new trivalent inactivated split-virus influenza vaccine in healthy Korean children: a randomized, double-blinded, active-controlled, phase III study. J Korean Med Sci. 2011;26(11):1421-7. http://dx.doi.org/10.3346/ jkms.2011.26.11.1421 PMID:22065897

38. Skowronski DM, Hottes TS, Chong M, De Serres G, Scheifele DW, Ward BJ, et al. Randomized controlled trial of dose response to influenza vaccine in children aged 6 to 23 months. Pediatrics. 2011;128(2):e276-89. http://dx.doi.org/10.1542/ peds.2010-2777 PMID:21768314

39. Vesikari T, Knuf M, Wutzler P, Karvonen A, Kieninger-Baum D, Schmitt $\mathrm{HJ}$, et al. Oil-in-water emulsion adjuvant with influenza vaccine in young children. N Engl J Med. 2011;365(15):1406-16. http://dx.doi.org/10.1056/NEJMoa1010331 PMID:21995388

40. Mitchell DK, Ruben FL, Gravenstein S. Immunogenicity and safety of inactivated influenza virus vaccine in young children in 2003-2004. Pediatr Infect Dis J. 2005;24(10):925 7. http://dx.doi.org/10.1097/01.inf.0000180978.66362.d9 PMID:16220095

41. Englund JA, Walter EB, Gbadebo A, Monto AS, Zhu Y, Neuzil KM. Immunization with trivalent inactivated influenza vaccine in partially immunized toddlers. Pediatrics. 2006;118(3):e57985. http://dx.doi.org/10.1542/peds.2006-0201 PMID:16950949

42. Neuzil KM, Jackson LA, Nelson J, Klimov A, Cox N, Bridges CB, et al. Immunogenicity and reactogenicity of 1 versus 2 doses of trivalent inactivated influenza vaccine in vaccine-naive 5-8-year-old children. J Infect Dis. 2006;194(8):1032-9. http:// dx.doi.org/10.1086/507309 PMID:16991077

43. Avila Aguero ML, Soriano-Fallas A, Umaña-Sauma MA, Ulloa-Gutierrez R, Arnoux S. Immunogenicity and tolerability of inactivated flu vaccine in high risk and healthy children. Medicina (B Aires). 2007;67(4):351-9. PMID:17891930

44. Schmidt-Ott R, Schwarz T, Haase R, Sander H, Walther U, Fourneau $M$, et al. Immunogenicity and reactogenicity of a trivalent influenza split vaccine in previously unvaccinated children aged 6-9 and 10-13 years. Vaccine. 2007;26(1):3240. http://dx.doi.org/10.1016/j.vaccine.2007.10.049 PMID:18022736

45. Chai WQ, Lu F, Chen $\mathrm{CH}$. [Adverse reaction and immune effect of split influenza virus vaccine in humans in 2005 and 2006]. Chinese Journal of Biologicals. 2008;21(2):139-42. Chinese.

46. Künzi V, Dornseiff $M$, Horwath J, Hartmann K. Safe vaccination of children with a virosomal adjuvanted influenza vaccine. Vaccine. 2009;27(8):1261-5. http://dx.doi.org/10.1016/j. vaccine.2008.12.008 PMID:19114080

47. Nolan T, Richmond PC, McVernon J, Skeljo MV, Hartel GF, Bennet J, et al. Safety and immunogenicity of an inactivated thimerosal-free influenza vaccine in infants and children. Influenza Other Respi Viruses. 2009;3(6):315-25. http://dx.doi. org/10.1111/j.1750-2659.2009.00108.x PMID:19903213

48. Vesikari T, Groth N, Karvonen A, Borkowski A, Pellegrini M. MF59-adjuvanted influenza vaccine (FLUAD) in children: safety and immunogenicity following a second year seasonal vaccination. Vaccine. 2009;27(45):6291-5. http://dx.doi. org/10.1016/j.vaccine.2009.02.004 PMID:19840662

49. Walter EB, Englund JA, Blatter M, Nyberg J, Ruben FL, Decker MD; GRC27 Study Team. Trivalent inactivated influenza virus vaccine given to two-month-old children: an off-season pilot study. Pediatr Infect Dis J. 2009;28(12):1099-104. http://dx.doi. org/10.1097/INF.ob013e3181bococa PMID:19935270

50. Wang X, Liu Y, Zhao YW. [Clinical trial on safety of inactivated split influenza virus vaccine, Anflu in 2007-2008]. Zhongguo Yi Miao He Mian Yi. 2009;15(5):443-6. Chinese.

51. D’Angio CT, Heyne RJ, Duara S, Holmes LC, O'Shea TM, Wang $\mathrm{H}$, et al. Immunogenicity of trivalent influenza vaccine in extremely low-birth-weight, premature versus term infants. Pediatr Infect Dis J. 2011;30(7):570-4. http://dx.doi. org/10.1097/INF.ob013e31820c1fdf PMID:21273938

52. Walker WT, de Whalley P, Andrews N, Oeser C, Casey M, Michaelis $L$, et al. $\mathrm{H}_{1} \mathrm{~N}_{1}$ antibody persistence 1 year afte immunization with an adjuvanted or whole-virion pandemic vaccine and immunogenicity and reactogenicity of subsequent seasonal influenza vaccine: a multicenter follow-on study. Clin Infect Dis. 2012;54(5):661-9. http://dx.doi.org/10.1093/cid/ cirgo5 PMID:22267719

53. Lambert SB, Chuk LM, Nissen MD, Nolan TM, McVernon J, Booy $R$, et al. Safety and tolerability of a 2009 trivalent inactivated split-virion influenza vaccine in infants, children and adolescents. Influenza Other Respi Viruses. 2013;7(5):676-85 http://dx.doi.org/10.1111/irv.12107 PMID:23551933

54. Salleras L, Dominguez A, Pumarola T, Prat A, Marcos MA, Garrido $P$, et al. Low reactogenicity of the virosomal subunit 
influenza vaccine in healthy children without risk factors. Vacunas. 2009;10(4):113-7.

55. Goodman MJ, Nordin JD, Harper P, Defor T, Zhou X. The safety of trivalent influenza vaccine among healthy children 6 to 24 months of age. Pediatrics. 2006;117(5):e821-6. http://dx.doi. org/10.1542/peds.2005-2234 PMID:16651286

56. Hambidge SJ, Glanz JM, France EK, McClure D, Xu S, Yamasaki K, et al.; Vaccine Safety Datalink Team. Safety of trivalent inactivated influenza vaccine in children 6 to 23 months old. JAMA. 2006;296(16):1990-7. http://dx.doi.org/10.1001/ jama.296.16.1990 PMID:17062862

57. Glanz JM, Newcomer SR, Hambidge SJ, Daley MF, Narwaney KJ, $\mathrm{Xu} \mathrm{S}$, et al. Safety of trivalent inactivated influenza vaccine in children aged 24 to 59 months in the vaccine safety datalink. Arch Pediatr Adolesc Med. 2011;165(8):749-55. http://dx.doi. org/10.1001/archpediatrics.2011.112 PMID:21810637

58. Armstrong PK, Dowse GK, Effler PV, Carcione D, Blyth CC, Richmond PC, et al. Epidemiological study of severe febrile reactions in young children in Western Australia caused by a 2010 trivalent inactivated influenza vaccine. BMJ Open. 2011;1(1):eooo016. http://dx.doi.org/10.1136/ bmjopen-2010-000016 PMID:22021725

59. Tse A, Tseng HF, Greene SK, Vellozzi C, Lee GM; VSD Rapid Cycle Analysis Influenza Working Group. Signal identification and evaluation for risk of febrile seizures in children following trivalent inactivated influenza vaccine in the Vaccine Safety Datalink Project, 2010-2011. Vaccine. 2012;30(11):202431. http://dx.doi.org/10.1016/j.vaccine.2012.01.027 PMID:22361304

6o. Brady RC, Hu W, Houchin VG, Eder FS, Jackson KC, Hartel GF, et al. Randomized trial to compare the safety and immunogenicity of CSL Limited's 2009 trivalent inactivated influenza vaccine to an established vaccine in United States children. Vaccine. 2014;32(52):7141-7. http://dx.doi.org/10.1016/j. vaccine.2014.10.024 PMID:25454878

61. Wood N, Sheppeard V, Cashman P, Palasanthiran P, Casacelli $M$, Cannings K, et al. Influenza vaccine safety in children less than 5 years old: the 2010 and 2011 experience in Australia. Pediatr Infect Dis J. 2012;31(2):199-202. http://dx.doi. org/10.1097/INF.ob013e31823d5303 PMID:22094632

62. Petousis-Harris H, Poole T, Turner N, Reynolds G. Febrile events including convulsions following the administration of four brands of 2010 and 2011 inactivated seasonal influenza vaccine in NZ infants and children: the importance of routine active safety surveillance. Vaccine. 2012;30(33):4945-52. http:// dx.doi.org/10.1016/j.vaccine.2012.05.052 PMID:22664224

63. Van Buynder PG, Frosst G, Van Buynder JL, Tremblay FW, Ross $A$, Jardine $C$, et al. Increased reactions to pediatric influenza vaccination following concomitant pneumococcal vaccination. Influenza Other Respi Viruses. 2013;7(2):184-90. http://dx.doi. org/10.1111/j.1750-2659.2012.00364.x PMID:22498052

64. European Medicines Agency (EMA). Withdrawal assessment report: Fluad Paediatric. Influenza vaccine, surface antigen, inactivated, adjuvanted with MF59C.1. London: EMA; 2012. Available from: http://www.ema.europa.eu/docs/en_GB/ document_library/Application_withdrawal_assessment report/2012/04/WC500126030.pdf

65. Sancho A, Melchiorri D, Abadie E; Committee for Medicinal Products for Human Use, European Medicines Agency. More on influenza vaccine in young children. N Engl J Med. 2012;366(26):2528-9, author reply 2528-9. http://dx.doi. org/10.1056/NEJMc1205643 PMID:22738111

66. Kaczmarek MC, Duong UT, Ware RS, Lambert SB, Kelly HA. The risk of fever following one dose of trivalent inactivated influenza vaccine in children aged $\geq 6$ months to $<36$ months: a comparison of published and unpublished studies. Vaccine. 2013; 31(46):5359-65. http://dx.doi.org/10.1016/j. vaccine.2013.09.005.

67. Watson JC, Hadler SC, Dykewicz CA, Reef S, Phillips L. Measles, mumps, and rubella--vaccine use and strategies for elimination of measles, rubella, and congenital rubella syndrome and control of mumps: recommendations of the Advisory Committee on Immunization Practices (ACIP). MMWR Recomm Rep. 1998;47(RR-8):1-57. PMID:9639369

68. Stockwell MS, Broder K, LaRussa P, Lewis P, Fernandez $\mathrm{N}$, Sharma D, et al. Risk of fever after pediatric trivalent inactivated influenza vaccine and 13-valent pneumococcal conjugate vaccine. JAMA Pediatr. 2014;168(3):211-9. http:// dx.doi.org/10.1001/jamapediatrics.2013.4469 PMID:24395025

69. CSL Biotherapies provides update on Fluvax investigation. Parkville: CSL Biotherapies; 2012. Available from: http://www. csl.com.au/s1/cs/auhq/1187378853299/news/1255929042869/ prdetail.htm

70. Maraskovsky E, Rockman S, Dyson A, Koernig S, Becher D, Morelli $A B$, et al. Scientific investigations into febrile reactions observed in the paediatric population following vaccination with a 2010 Southern Hemisphere Trivalent Influenza Vaccine.
Vaccine. 2012;30(51):7400-6. http://dx.doi.org/10.1016/j. vaccine.2012.09.083 PMID:23063831

71. Jefferson T, Rivetti A, Di Pietrantonj C, Demicheli V, Ferroni E. Vaccines for preventing influenza in healthy children. Cochrane Database Syst Rev. 2012;8:CDo04879. PMID:22895945

72. European Medicines Agency (EMA). European Medicines Agency updates guidance for annual strain change of seasonal influenza vaccines. London: EMA; 2014. Available from: http://www.ema.europa.eu/ema/index.jsp?curl=pages/ news_and_events/news/2014/02/news_detail_002019. jsp\& $\mathrm{mid}=\overline{\mathrm{W}}$ Cobo1ac058004d5C1

73. European Medicines Agency (EMA). Interim guidance on enhanced safety surveillance for seasonal influenza vaccines in the EU London: EMA; 2014. Available from: http://www. ema.europa.eu/docs/en_GB/document_library/Scientific_ guideline/2014/04/WC500165492.pdf

74. Pavia-Ruz N, Angel Rodriguez Weber M, Lau YL, Nelson EA, Kerdpanich A, Huang LM, et al. A randomized controlled study to evaluate the immunogenicity of a trivalent inactivated seasonal influenza vaccine at two dosages in children 6 to 35 months of age. Hum Vaccin Immunother. 2013;9(9):1978-88. http://dx.doi.org/10.4161/hv.25363 PMID:23782962

75. Frey SE, Bernstein DI, Gerber MA, Keyserling HL, Munoz FM, Winokur PL, et al. Safety and immune responses in children after concurrent or sequential $2009 \mathrm{H}_{1} \mathrm{~N}_{1}$ and 2009-2010 seasonal trivalent influenza vaccinations. J Infect Dis. 2012;206(6):828-37. http://dx.doi.org/10.1093/infdis/jis445 PMID:22802432

76. Moher D, Liberati A, Tetzlaff J, Altman DG; PRISMA Group. Preferred reporting items for systematic reviews and meta-analyses: the PRISMA statement. PLoS Med. 2009;6(7):e1000097. http://dx.doi.org/10.1371/journal. pmed.1000097 PMID:19621072 